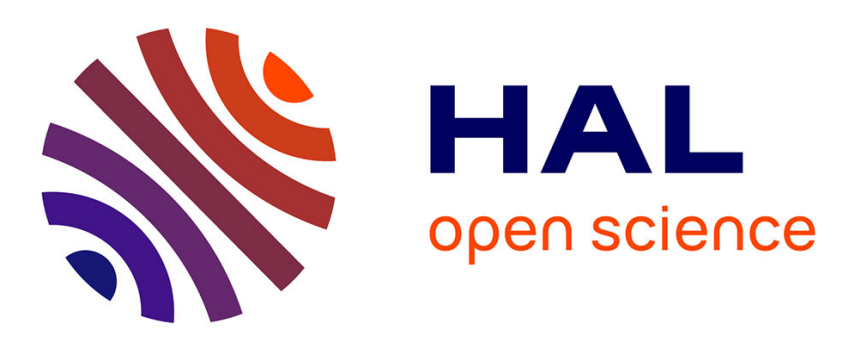

\title{
Designing REDD+ contracts to resolve additionality issues
}

Mireille Chiroleu-Assouline, Jean-Christophe Poudou, Sébastien Roussel

\section{To cite this version:}

Mireille Chiroleu-Assouline, Jean-Christophe Poudou, Sébastien Roussel. Designing REDD+ contracts to resolve additionality issues. Resource and Energy Economics, 2018, 51, pp.1-17. 10.1016/j.reseneeco.2017.10.004 . halshs-01643656

\section{HAL Id: halshs-01643656 \\ https://shs.hal.science/halshs-01643656}

Submitted on 21 Nov 2017

HAL is a multi-disciplinary open access archive for the deposit and dissemination of scientific research documents, whether they are published or not. The documents may come from teaching and research institutions in France or abroad, or from public or private research centers.
L'archive ouverte pluridisciplinaire HAL, est destinée au dépôt et à la diffusion de documents scientifiques de niveau recherche, publiés ou non, émanant des établissements d'enseignement et de recherche français ou étrangers, des laboratoires publics ou privés. 


\title{
Designing REDD+ Contracts to Resolve Additionality Issues*
}

\author{
Mireille Chiroleu-Assouline ${ }^{\dagger \ddagger} \quad$ Jean-Christophe Poudou ${ }^{\S} \quad$ Sébastien Roussel ${ }^{1 * * *}$
}

July 18, 2017

\footnotetext{
*Acknowledgements: Participants at the following Conferences, Workshops and Seminars are thanked for their useful comments: the 19th Annual EAERE Conference (Prague), the 61rst Annual AFSE Congress (Paris), the 22nd Annual CREE Conference (Vancouver), the 2nd Bi-Annual ENRMDTE Conference (Clermont-Ferrand), the Environmental Economics Meeting - CRESE (Besançon) Workshop, the LAMETA-PERENE Seminar (Montpellier), the TSE-LERNA Seminar (Toulouse), the Ecole Polytechnique Environmental Economics Seminar (Paris) as well as the LEF (Nancy) Seminar. We would like to thank in particular Hassan Benchekroun, Philippe Delacote, Michel Moreaux, François Salanié and James Vercammen. Finally we thank Stefan Ambec and two anonymous reviewers for useful comments. The usual disclaimers apply. Financial support from the program Investissements d'Avenir of the French government (ANR-10-LABX-93-01) is gratefully acknowledged.

${ }^{\dagger}$ Corresponding author. Address: Paris School of Economics (PSE) - Université Paris 1 Panthéon-Sorbonne, PjSE, 48 bd Jourdan, 75014 Paris, France, E-mail: Mireille.Chiroleu-Assouline@univ-paris1.fr

${ }^{\ddagger}$ Economie Publique, INRA, AgroParisTech, Université Paris-Saclay, 78850 Thiverval-Grignon, France.

${ }^{\S}$ LAMETA, Univ. Montpellier, CNRS, Univ. Paul Valéry Montpellier 3, INRA, SupAgro, F-34000 Montpellier, France. E-mail: jean-christophe.poudou@umontpellier.fr

${ }^{\top}$ Labex Entreprendre, Univ. Montpellier, ANR-10-LABX-11-01, F-34000 Montpellier, France.

"LAMETA, Univ. Paul Valéry Montpellier 3, CNRS, Univ. Montpellier, INRA, SupAgro, F-34000 Montpellier, France. E-mail: sebastien.roussel@univ-montp3.fr, sebastien.roussel@lameta.univ-montp1.fr

** Labex CeMEB, ANR-10-LABX-0004, F-34000 Montpellier, France.
} 


\begin{abstract}
To address the issue of potential information asymmetries inherent in the estimation of deforestation baselines required by the current Reducing Emissions from Deforestation and Forest Degradation $+($ REDD +$)$ scheme, we offer a theoretical analysis of an extended scheme relying on the theory of incentives. We compare two types of contracts: a deforestation-based contract and a policy-based contract. Each of them implies a dramatically different information rent / efficiency trade-off due to domestic implementation and transaction costs. If the contract is deforestation-based (resp. policy-based), information rents are awarded to countries with the $e x$ ante lowest (resp. highest) intended deforestation. We show that a general contract can be offered to recipient countries in which the type of instrument proposed is endogenous, independent of the historical trend, unlike the current REDD + mechanism. Dividing countries into two groups corresponding to the deforestation-based instrument and the policy-based instrument helps the donor country to obtain efficient deforestation and avoided deforestation levels.
\end{abstract}

JEL classification: D82, O13, Q23, Q54.

Keywords: Conditionality, Contract, Deforestation, Hidden Information, Incentives, Performance, Reducing Emissions from Deforestation and Forest Degradation $+($ REDD +$)$. 


\section{Introduction}

One of the primary sources of carbon emissions is deforestation and forest degradation, which is responsible for total anthropogenic greenhouse gas emissions of approximately $12 \%$ (van der Werf et al. (2009), IPCC (2014)). These emissions are the second highest human-induced source of climate change (Lederer (2011)). There is an urgent need to cope with deforestation because induced climate change costs were estimated to increase to US\$ 1 trillion by the 2100 time horizon (Eliasch (2008)). According to Kindermann et al. (2008), curbing deforestation is not an infeasible task, and Eliasch (2008) states that $3.5 \mathrm{Gt} \mathrm{CO}_{2}$ could be saved per year in the forest sector at relatively low cost compared to the abatement alternatives in other sectors. Consequently, to address the deforestation and forest degradation issue, the international community has been promoting the Reducing Emissions from Deforestation and Forest Degradation $+(\mathrm{REDD}+)$ scheme as a part of the post-Kyoto architecture. ${ }^{1}$

After being introduced at the international level as a proposal at the 11th Conference Of the Parties (COP11) to the United Nations Framework Convention on Climate Change (UNFCCC) in Montreal 2005, the REDD scheme was conceptualized at COP13 in Bali 2007, extended to REDD + in 2008 by the Subsidiary Body for Scientific and Technological Advice (SBSTA) established at COP13, and it became a formal policy at COP19 in Warsaw 2013. The original idea of the REDD + scheme is rather simple and intuitive: developed countries delegate a part of their climate change mitigation obligations to developing countries through a contract by rewarding them to implement reductions in carbon emissions from forests, while covering their opportunity costs to do so by potentially altering their development paths or at least by stopping some of the marginally profitable forest conversion. This payment occurs either through a direct monetary transfer or through carbon offsets or credits saleable on the carbon market. The payment-basis lies in per unit reductions of deforestation in comparison to a baseline that needs to be agreed upon. As a consequence, the additionality issue is crucial because the contract must ensure that "one is only paying for emissions reductions or stock enhancements that come on top of what would have happened without the contract" (Angelsen (2010)). According to Karsenty and Ongolo (2012), the originality of REDD + lies in its incentive properties because it intrinsically rewards states for their achievements in actions against deforestation. However the additionality issue gave rise to an intense debate, that underlined the risk of rewarding tropical hot air, i.e., avoided deforestation that would also have been achieved without the REDD+

\footnotetext{
${ }^{1}$ In this paper, we refer for simplicity to REDD + that extends the original REDD scheme to conservation of forest, sustainable management of forest and forest enhancement.
} 
contract (Angelsen (2008a)).

The aim of this paper is to complement the pragmatic approaches adopted until now with a theoretical analysis to propose a cost-efficient alternative REDD + mechanism, that avoids the inefficiencies of the current agreements due to potential information asymmetries. The objectives are then to take explicitly into account the risk of hot air due to ex ante asymmetric information and to theoretically design the ideal cost-efficient REDD + scheme as a contractual relationship between countries in the light of the theory of incentives. To the best of our knowledge, there is no analytical paper of the REDD + scheme in terms of the theory of incentives with a PrincipalAgent relationship under this kind of asymmetric information ${ }^{2}$ and exogenous implementation and transaction costs.

In the literature however, several studies have been interested in climate change mitigation and low cost policies compared to costly abatement of fossil fuel emissions, particularly regarding avoided deforestation (Heal and Conrad (2006), Murray et al. (2009), Combes-Motel et al. (2009), Murray et al. (2013)). With regards to tropical deforestation, van Soest and Lensink (2000) underline how conditionality on international aid transfers can improve short-run and long-run forest conservation. In a dynamic setting, they propose a transfer function that rewards developing countries both positively with the forest stock and negatively with the deforestation rate. Further to this approach, Ollivier (2012) studies the REDD + mechanism as an international transfer and its impacts in the long-run on developing countries' growth. She analyzes the impacts of low and high transfer schemes to prevent agricultural land expansion and the interplay with the manufacturing sector.

In a contractual perspective, Karsenty and Ongolo (2012) describe literally how the theory of incentives is at the core of the REDD + scheme, whereas Kerr (2013) and Angelsen (2017) propose to design results-based agreements and result-based aid (RBA), respectively, for REDD + through a Principal-Agent framework. However, they do not consider formally incomplete information issues in using this framework. From our side, we distinguish our approach while using the theory of incentives with a Principal-Agent relationship in designing contracts with informational issues (Laffont and Martimort (2002)). This approach has been used by Martimort and Sand-Zantman (2016) in the context of multinational environmental agreements, by Mason and Plantinga (2013) to address the additionality issue raised by carbon offsets in the contracts offered by a government to landowners to induce carbon sequestration in forests, and by Horowitz and Just (2013) in the

\footnotetext{
${ }^{2}$ Because we want to focus on the impact of asymmetric information, we do not consider the uncertainties about the future values of the drivers of deforestation; these uncertainties are shared between parties.
} 
case of payments for environmental services to agricultural firms. ${ }^{3,4}$ Plantinga and Richards (2010) acknowledge the additionality issue implied by the REDD + contracts and propose to replace the historical deforestation baselines with negotiated baselines to induce participation and to mitigate the adverse selection issue.

Building on a thorough analysis of the REDD + scheme, we show how the confusion between the concepts of business-as-usual deforestation path and of reference levels can lead to reward hot air for some countries, and we propose on the contrary to base the contract only on observable variables. Even though we acknowledge that some moral hazard may also plague the relationship between a recipient country and landowners, mainly at the implementation stage, we concentrate on the adverse selection issue essentially because the latter has not been studied yet in this context whereas the former has already been broadly analyzed in the literature. ${ }^{5}$ As a consequence, we analyze the REDD + mechanism in a reduced form way, considering that, within the recipient country, the subnational hierarchical relationships are conducted in an efficient way. We consider thus two types of contracts: a deforestation-based contract $(D C)$ different from the current REDD + contract, and a policy-based contract $(P C)$ corresponding to proposals arising in the literature and policy papers through the adoption of policy reforms to avoid deforestation. We discuss further the menus of contracts a developed country should offer in terms of environmental efficiency regarding a developing country's hidden information and expected welfare.

From our analytical framework, we obtain several important results. First, we can state that the type of REDD + contract proposed creates a different information rent / efficiency trade-off, the difference being amplified because we take account of implementation, governance and transaction costs of domestic policies (their crucial role has been underlined by Alston and Andersson (2011) or Laing and Palmer (2015)). If the contract is deforestation-based, information

\footnotetext{
${ }^{3}$ Sheriff (2009) proposes an empirical methodology to calibrate such a second-best land conservation mechanism.

${ }^{4}$ Note that there is an extensive literature dedicated to the optimal conservation programs in analyzing optimal compensation schemes at the farm level to overcome information asymmetry between farmers and governments, see Wu and Babcock (1996) and Arguedas and van Soest (2011) among others.

${ }^{5}$ For example, MacKenzie et al. (2012) analyze international carbon sequestration contracts as enforcementproof incentive schemes in which a buyer provides an investment for afforestation or reforestation projects to a seller in a developing country. In their framework, the buyer demands a guaranteed delivery of productive level, using a two-tiered payment scheme while facing moral hazard in precaution, limited liability of parties and the potential for opportunistic contract breach. They show that attributing liability to the buyer yields inefficiently low levels of investment in carbon sequestration. Cordero-Salas and Roe (2012) and Cordero-Salas et al. (2016) study how REDD + contracts should induce carbon offsets storage over time with self-enforcing contracts, under ex post asymmetric information. They consider additionality and permanence issues in a contractual dynamic setting, especially regarding institutional differences among the countries in which the contracts will be implemented. They show that efficient levels of additionality can be achieved even when the buyer is uncertain about the landholder's opportunity cost of conservation whereas the value of conservation is sufficiently high relative to the opportunity cost.
} 
rents are awarded to countries with the ex ante lowest projected deforestation to encourage them to induce the highest efficiency while coping with deforestation. If the contract is policy-based, then the rent-efficiency trade-off occurs in the opposite way and the optimal scheme implies tackling forested countries with the ex ante highest projected deforestation. This result is in line with general findings in agency theory dealing with hidden information regarding the efficiency of input versus output incentive schemes with countervailing incentives created by the choice of the instrument (Bontems and Bourgeon (2000)), despite the distinctive features of our setting (typedependent reservation utility of the Agent and sensitivity of the Agent's utility to the output), but it had never been stated before in the debate about the appropriate design of REDD + contracts. Second, upon comparing these contracts, there is a business-as-usual baseline threshold in terms of environmental effectiveness concerning less deforestation. We show that a general contract can be offered to developing countries in which the type of instrument proposed is endogenous. Dividing countries into two groups, that choose either the deforestation-based instrument or the policy-based instrument, helps the developed country to obtain efficient deforestation and avoided deforestation levels. As a consequence, our paper strengthens the case of conditionalitybased contracts, as advocated by Combes-Motel et al. (2009) or Karsenty and Ongolo (2012), but only for the developing countries with high projected deforestation baselines, which may not be strictly correlated to their historical trend. It does not encroach on the country's sovereignty because the contract is freely chosen and incentive-compatible.

The remainder of this paper is organized as follows. In Section 2, we provide key elements of understanding regarding additionality and conditionality to motivate our approach. In Section 3, we present our alternative mechanism progressively: we first show the equivalence between the deforestation-based contract and the policy-based contract under perfect information and how the current REDD + contract entails incentives for some countries to inflate their deforestation baseline; we analyze then the general contract that can be offered by the donor and we provide a numerical example to emphasize the efficiency gains provided. Section 4 concludes.

\section{Analysis of the current REDD+ contract}

Being grounded as a performance-based scheme, the REDD + scheme employs a phased approach (Zarin et al. (2009), Ollivier (2012), Angelsen (2017)). Phase 1 establishes readiness and capacity building to define a state-of-the-art of carbon stocks and deforestation levels against which performance should be assessed. Phase 2 defines strategies and policies to address the 
deforestation drivers focused to implement of a REDD + strategy, to support national policies. Phase 3 corresponds to a compensation phase for the developing countries based on performance achieved in reducing deforestation (results-based payments). Funding sources from developed countries currently envisage financing mainly the compensation phase apart from the readiness phase. $^{6}$ In this paper, we focus on national or jurisdictional initiatives between countries towards REDD,$+{ }^{7}$ since at the project and local level additionality issues may be addressed more specifically through existing certification schemes ${ }^{8}$ (Chagas et al., 2013).

\subsection{Additionality and baseline setting}

The additionality issue depends critically on the level of the baseline used for rewarding the efforts of the deforesting countries. The baseline's practical determination gave rise to a great debate among academics and practitioners (Angelsen (2008a) and (2008b), Huettner et al. (2009), Obersteiner et al. (2009), Gregersen et al. (2010), Ekins et al. (2011)). Following the terminology used in the literature, and specifically in Angelsen (2008a), the reductions of deforestation should be measured and compared to a business-as-usual (BAU) deforestation scenario as a baseline, defined as a projected deforestation path that would be pursued if no REDD + contract was signed. Such a counterfactual scenario depends on the trade-off for the country, at the national and sub-national level, between growth (or poverty alleviation) and forest conservation, which can be thought of as a global opportunity cost of forest conservation, at country-scale. Designing the counterfactual scenario is called a "thorny issue" by Karsenty et al. (2014), ${ }^{9}$ who underline that the BAU baseline is affected both by inherent uncertainties (unknown future values of drivers of deforestation and uncertain relationship between such drivers and agricultural land) and asymmetric information about the potential conservation projects, but even more about the development objectives of the deforesting country and the policies that it would like to implement.

Facing the difficulty of establishing such a BAU baseline taking account of all of the current

\footnotetext{
${ }^{6}$ At COP19, the adopted Framework by the Parties states the following: funding may come from multiple sources, i.e., public and private, countries or international funds and companies, in a bilateral or a multilateral manner; however, developing countries should provide information on how they have respected their commitment before receiving their compensation payments.

${ }^{7}$ For example, the international law-based initiatives such as the Green Climate Fund within the UNFCCC to contribute to global climate change mitigation; the multilateral initiatives such as the Forest Carbon Partnership Facility - Carbon Fund; or, the bilateral initiatives such as the Norway's International Climate and Forest Initiative through the Norway - Guyana REDD + Investment Fund and the Indonesia - Norway REDD + partnership).

${ }^{8}$ However we may note that this remains rather imperfect (Seyller et al., 2016).

${ }^{9} \mathrm{~A}$ similar issue occurs with other mechanisms intended to help in climate change mitigation that rely on the determination of a counterfactual scenario, such as Joint Implementation (Wirl et al. (1998)) or Clean Development Mechanism (Lederer (2011)).
} 
and future national drivers of deforestation, an agreement was reached at COP17 in Durban in 2011 about a pragmatic determination of a reference level (RL) relying on the extrapolation of historical deforestation trends. ${ }^{10}$ Such an approach is usually viewed as a conservative one that ensures that additionality is considered (Chagas et al. (2013)). To cope with the criticism that extrapolating the historical deforestation trends is likely to underestimate the future BAU deforestation for countries at the early stages in the forest transition ${ }^{11}$ but overestimate BAU deforestation for countries at the later stages, proposals were made either to include a development adjustment factor (DAF) (Coalition for Rainforest Nations) or to take into account the "common but differentiated responsibilities" of countries in the collective fight against climate change (Zarin et al. (2009)). As a result, following the guidance of the COPs, all RLs are expected to rely on historical data, with potential adjustments due to national circumstances that require a detailed justification. Among the diverse financing institutions for results-based REDD + actions, only the Forest Carbon Partnership Facility - Carbon Fund has provided guidance, the Carbon Fund Methodological Framework, that strictly limits the adjustments: for a high deforestation country, the RL cannot exceed the average annual historical emissions over a reference period; for a low deforestation country, the RL may be adjusted upward by at most $10 \%$ above average annual historical emissions. However, according to the Food and Agriculture Organization of the United Nations (FAO (2014)), all submitted RLs until now to the Carbon Fund correspond to the maximum upward limit allowed: 10-year average of historical data for historically deforesting countries (Brazil, Chile, Ghana, Nepal, Vietnam) or adjusted for all of the High Forest cover, Low Deforestation countries involved (Democratic Republic of Congo, Guyana, Republic of Congo). ${ }^{12}$

We can offer two explanations for this evidence. Either all considered countries really projected, in case of no REDD + agreement, to maintain future deforestation paths higher or at least equal to their historical trend but they find nevertheless profitable to participate because they can envisage to do better enough than this trend with REDD + funds. Or, some of these

\footnotetext{
${ }^{10}$ Busch et al. (2012) acknowledge the impossibility of establishing whether econometric modelling outperforms extrapolation of historical trends in predicting future emissions. They advocate for future research that should investigate what combination of historical trends, observable geographic characteristics, planned policies and local insights would provide the most accurate prediction of future emissions.

${ }^{11}$ According to the forest transition hypothesis, due to Mather (1992), the rate of deforestation decreases over time because the opportunity costs of deforestation rise with increased forest scarcity, inducing in all countries a change from deforestation to a stable or increasing forest cover.

${ }^{12}$ The bilateral negotiation between Norway and Guyana has often been provided as an example of inflated RL: the actual annual average deforestation rate over the 2000-2009 period was bound to 0.03\% per year whereas Guyana has obtained a contractual commitment with Norway on a $0.275 \%$ per year basis worth US\$250 million in compensation transfers. One can presume that Guyana's real RL has been inflated and that Guyana will probably earn some rents from its private information, even if this bargaining outcome was allowed by the urgent need for Norway to start their REDD+ activities.
} 
countries had by themselves, being in a later stage of the forest transition (Angelsen (2008b)) or for other domestic reasons, projected a lower deforestation path but they take the opportunity to get the highest possible reward in the REDD + agreement. Without any intangible proof, there is at least a strong suspicion that some countries may earn some information rents caused by private information about their BAU baselines. This is also highlighted by Kerr (2013) or Wong et al. (2016), and by Seyller et al. (2016) in the case of REDD + projects. The next subsection provides an extensive analysis of that case, where the information rents are not eliminated but only bounded by the currently proposed guidance for the determination of the RLs. The current REDD + contracts appear therefore to be designed in order to mitigate this asymmetric information problem, but we will show in Section 3 that they remain sub-optimal. This feeds into the debate about the appropriate way to design REDD + as incentive contracts inducing the recipient countries to reveal their private information, and rewarding them according to their actual efforts.

\subsection{For a results-based contract relying on observed deforestation rather than on estimated avoided deforestation}

The main drawback of the REDD + contracts is that, despite they intend to be results-based, they actually reward uncertain results, namely an avoided deforestation estimated as the difference between the observed deforestation and a negotiated or at least projected crediting baseline. Figure 1 presents a variant of a figure often used to present the estimation of the RLs (Angelsen (2008b)): we insist on the differences between observable and evaluated variables in case of discrepancy between the BAU baseline and the concept of RL defined in the current literature. This figure represents the case stated previously of a country that projects a lower future deforestation path than their historical trend. Such an autonomous change in the deforesting behavior may be due to many causes, including changes in domestic policies, agriculture intensification or reduced needs for deforestation in order to alleviate poverty.

\section{Insert Figure 1}

At time $T$ of the contract implementation, provisionally to the capacity building developed in the readiness phase (as the first phase of the REDD + phased approach), the forest cover $\phi$ is the only observable information for the recipient country or equivalently, the historical deforestation trend until this date. At the end of the contract, the realized path can also be 
observed. The current mechanism recommends the use of the projection of the historical trend as a RL for rewarding avoided deforestation. If, instead of projecting the same deforesting pace for the future without any REDD + contract, and thus a perfect status quo, the recipient country projects another developing path implying less deforestation than before $T$, the slope of her BAU baseline is lower, and the path is closer to a constant forest cover $\phi$, as represented in Figure 1. This BAU baseline is characterized by the amount of deforestation $\theta$ that would thus be privately achieved after the contract duration by the eligible country, depending on her economic growth and development, her demographic growth, regulation enforcement, timber export prices, climatic events, etc., as explained in Combes-Motel et al. (2009). Realizing this BAU baseline may also result from political willingness to enforce or implement regulations, and impose opportunity costs to the deforesting country. These costs are imperfectly known by the donor, or at least better known by the recipient, which is the source of incomplete information between parties. Let us now assume that the REDD + agreement enables the recipient country to achieve an even lower realized deforestation path. If we denote $d$ the deforestation realized at the end of the contract, the realized avoided deforestation $a$ is equal to $\theta-d$. This avoided deforestation is the true measure of the effort done by the recipient, who should be rewarded for it. However, as soon as the historical trend (adjusted for the previously low deforesting countries) has been chosen as a "conservative" RL against which the performance is to be measured, it is clear from the figure that some hot air will also be rewarded: in this case, considering the RL to be identical to the deforestation BAU baseline allows remaining informational rent to countries with lower BAU baselines than their historical trends. They have incentives not to disclose their true BAU baseline and to accept the reward against RL. On the contrary, for countries with higher BAU baselines $\theta$ (with a path lower than RL, not represented in Figure 1 to keep it clear), there is no opportunity left to be rewarded for any hot air nor for their whole effort. In this case the RL can be interpreted as the upper bound set by the international community to the accepted ex post deforestation under the REDD + contract. From these observations, we argue that a performance-based contract should rather be based on observable variables, such as the realized deforestation $d$, instead of on estimated variables measured against an ad hoc RL.

\subsection{Alternative proposal: conditionality to domestic policies}

REDD + payments leave the choice of policy instruments to the recipient countries. Karsenty and Ongolo (2012) call REDD + payments as non conditional, since they are not related to the adoption of policy measures or changes in the legal or institutional framework. REDD + is 
then "not encroaching on the sovereign discretion of nations to design acceptable and adequate policies and measures nationally" (Streck (2010)). These payments are actually conditional to results instead of policies. Karsenty and Ongolo (2012) advocate for an alternative architecture for REDD + relying on conditionality for carbon payments, i.e., payments based on the implementation of policies and measures targeting the drivers of deforestation. By addressing the structural causes of deforestation and degradation, they state that REDD + payments could "be used as an investment instrument for funding policies on specific and ambitious programs able to tackle the major structural problems that underlie much of deforestation in such countries: agriculture, land, the means and the functioning of justice and of the administration of control". They argue that conditionality would help to address the additionality issue. One of our aims is to theoretically assess the effectiveness and efficiency of a REDD + scheme incorporating this proposal. In the widest sense of the word, conditionality generally refers to the use of conditions imposed by the donors on the recipients for the allocation of funds. ${ }^{13}$ These conditions are built on agreed terms and commitments to obtain a desired outcome. In this sense, conditionality has been emphasized by Drazen (2002) as really helpful for reform-minded governments who need to overcome internal opposition, as it can be the case for countries projecting a high deforestation BAU baseline.

As underlined by Angelsen (2017), result-based aid (RBA) includes in its broad sense the various forms of conditional payments and not solely those based upon results. From our side, we separate the results-based aid (through a deforestation-based contract) from the domestic policy-based aid (through a policy-based contract) that is built on policy reforms incentives. More precisely, policy-based aid is to be conditioned to the adoption of policy reforms that can be divided into direct and enabling activities, both needed and essential, as underlined by Salvini et al. (2014). Direct interventions are specific, often local activities which result in a direct change in the forest cover (i.e., reforestation, protected area strategies, agricultural intensification to reduce pressure on forests). Enabling interventions are aimed at facilitating the implementation of direct interventions (i.e., improved law enforcement against illegal logging, and land tenure regulation). The efficiency of interventions addressing the direct drivers is conditioned by the implementation of policies addressing the critical underlying drivers. These drivers are identified as keys to the design of domestic policies by Pfaff et al. (2013), who, referring to Kerr (2013), underline that

\footnotetext{
${ }^{13}$ In this paper, we do not use the term of conditionality in the broad sense of "conditioned to something" and opposite to "unconditional" (as Azam and Laffont (2003)) but in the same narrow sense as Karsenty and Ongolo (2012) and the REDD + community, meaning that the payments are conditional to domestic policies (and not to results of these policies).
} 
implementing this kind of domestic policies generate "incremental costs" for forested countries that could be covered by REDD + funds.

Lessons from previous and current experiences in the broader field of development aid can help design the domestic policy-based contracts for REDD + . Debt-for-nature swap, initiated in the 1980s aims to allow a developing country to use an environmental trust fund through the renegotiation of her external debt by the creditor (van Soest and Lensink (2000), Kerr (2013)). This provides capital used to complete policy reforms. However, this is a once-and-for-all funding in which sanctions are limited and sound governance principles are needed in recipient countries to obtain success, which can hamper its applicability to REDD + mechanisms. The Global Environment Facility (GEF) initiated by the World Bank, the United Nations Environment Programme and the United Nations Development Programme during the 1990s promotes and supports activities for environmental protection in particular regarding biodiversity, climate change, international waters and land degradation. Forests conservation activities are eligible for funding and, unlike the debt-for-swap mechanism funds, are provided periodically (van Soest and Lensink (2000)). GEF funds are available to developing countries and countries with economies in transition to meet the objectives of the international environmental conventions and agreements. They may be provided with technical assistance to government agencies, among different potential partners, and they are specifically linked to precise implementation plans of projects or programs in recipient countries. Finally, conditional loans have been widely used as an instrument enhancing policy reforms, with mixed success (Collier et al. (1997)) as for example in the Structural Adjustment Program (SAP) supported by the World Bank and the International Monetary Fund. Some inspiration can also be taken in the analysis by Ohler et al. (2012) of the experiment conducted by the Millenium Challenge Corporation, which explicitly intended to strengthen the reform-mindedness of possible recipient countries through selectivity in granting aid exclusively to needy and well performing recipients.

It is worth noting that some recent initiatives within the REDD + mechanism are currently already conditioned to policy changes. Angelsen (2017) shows that the bilateral experiences of Norway with respectively Guyana and Indonesia lead to a RBA designed on conditional aids in addition to payments for emission reductions (with respect to Phase 2 and Phase 3 of the REDD+ phased approach). In Brazil, the climate mitigation efforts will be strengthened by Norway with an offer worth US\$1 billion in funding through the Amazon Fund managed by the Brazilian Development Bank, with most conditional on continued success. More generally, conditional fundings could be attached to given policy reforms, which are decided jointly by the donor and 
the recipient, that would target the potential drivers of deforestation and forest degradation. Whereas the SAP has been contested for encroaching of the sovereignty of the recipients, it would be less the case for REDD + fundings based on negotiated specific interventions. Their efficiency could be strengthened through a phasing of financial support in successive tranches contingent on progress in achieving policy adjustments, as in international aid programs (Collier $(1997))$.

\section{A new design proposal for the REDD + contract}

The measure of actual results of policies aiming at reducing deforestation and forest degradation depends currently both on the possibility to monitor the output and on the RL used to measure the avoided deforestation. We argue that it is much more consistent and cost-efficient to consider only observable variables instead of basing contracts on constructed variables compared to announced RLs. We disentangle these two components by assuming that the BAU deforestation baseline is privately known by the recipient, which can jeopardize additionality, and that performance monitoring could be achieved either by observing deforestation levels or by controlling policy levers implemented by the recipient country. Output monitoring implies measuring forest coverage and the quality of this coverage. Obtaining precise measures is not impossible but it is costly. Monitoring the domestic policies themselves, as asked by Karsenty and Ongolo (2012), or the drivers (Salvini et al. (2014)) might appear easier but also entails high costs. ${ }^{14}$ Even if deforestation alone can be rather easily monitored (through observation satellite), it is not the case for forest degradation and we consider in this paper that both deforestation and forest degradation or domestic policies to avoid them are similarly, if not equally, costly to monitor. Facing these monitoring costs, the Principal in a Principal-Agent framework must decide which variable to observe during the contract, and making this instrument contractible depends on the cost (measurement cost and enforcement cost). This leads the Principal to propose either a contract based on realized deforestation or a contract based on policy implementation to avoid deforestation. These two contractual relationships are connected to respectively output and input incentive schemes. ${ }^{15}$ The model that we design can be viewed as a joint adaptation of the adverse selection models of Laffont and Tirole (1986) and Bontems and Bourgeon (2000)

\footnotetext{
${ }^{14}$ This involves process indicators with completion of national REDD + plan or Free Prior Informed Consent (FPIC) consultations through meetings, expertise, etc. (Angelsen (2017)).

${ }^{15}$ These contractual relationships were formerly analyzed by Maskin and Riley (1985) and Bontems and Bourgeon (2000). These papers point out the superiority of output-based schemes over input-based schemes in asymmetric informational contexts, except in case of countervailing incentives.
} 
to the specific setting of REDD + schemes, that includes distinctive features. Both contracts are incentive feasible and may offer a cost-efficient operational way to implement the REDD+ scheme.

\subsection{An agency model and the benchmark case under perfect information}

The REDD + scheme establishes a bilateral relationship between a developed country or a supranational funding institution centralizing contributions by developed countries, which is identified as the donor in the REDD + terminology, and a developing country identified as the recipient. Using usual terms of the theory of agency, the donor acts as a Principal and the developing country as an Agent of the agency relationship created by the REDD + arrangement, respectively.

In this contractual relationship between the donor and the recipient, the objectives can be summed up in the following way: the aim of the donor is to mitigate climate change by indirectly reducing deforestation and forest degradation (mainly tropical forests) while delegating this task to the recipient; the aim of the recipient is in turns to stimulate her economic growth while controlling deforestation according to a set of thresholds regarding her commitment with the donor. The recipient is a priori capable of modifying deforestation levels but incurs opportunity costs due to potential growth loss, imperfectly known by the donor, which is the source of incomplete information between parties. Reducing the deforestation level also gives rise to some implementation and transaction costs in the recipient country. To create incentives to reduce deforestation and forest degradation, the donor offers a contract which if it is signed, covers the recipient's costs, and alters her economic growth.

We use as a key variable, the type $\theta \in[\underline{\theta}, \bar{\theta}]$ that represents the BAU baseline for deforestation and forest degradation projected by the recipient (see Figure 1), with $\underline{\theta}>0$ and $\bar{\theta}<\phi$, where the parameter $\phi>0$ is assumed to represent the total forest (observable) surface available in the recipient's country at the implementation time $T$ for the contract. Since there is no opportunity of an informational rent for BAU baseline higher than the historical trend (adjusted if the country was previously a low deforesting one), $\bar{\theta}$ is equal to this upper bound RL. Moreover, to keep things simple, we assume that no deforesting country with a BAU baseline higher than $\bar{\theta}$ could find profitable to participate in the scheme. As usual in contract theory, $\theta$ is distributed with respect to the cumulative distribution function $F(\theta)$, which is a log-concave common prior, with the associated density function $f(\theta) .{ }^{16}$

The ex post deforestation level is represented by a positive continuous choice variable, $d$

\footnotetext{
${ }^{16}$ The log-concavity assumption ensures that associated hazard rates are decreasing in $\theta$. Many univariate parametric families of probability distributions are log-concave, including the normal law.
} 
which depends on the recipient's actual decisions to avoid deforestation that are set by domestic policies. ${ }^{17}$ They are represented by a continuous choice variable $a \geq 0$ such that deforestation level is then the difference:

$$
d=\theta-a
$$

Within this formulation, the avoided deforestation is merely identified to the decisions $a$. Hence, except for the recipient, it is not possible (or it is costly) to distinguish between the contribution of the privately known type $\theta$ and the actual domestic policies and measures to avoid deforestation $a$. These policies and measures refer to public policies such as forest conservation through national parks and the fight against corruption and illegal logging. They also refer to agricultural policies or road infrastructures with potential effects.

The avoided deforestation $a$ is costly for the recipient, which incurs not only the global opportunity cost of the "lost" deforestation but also implementation and domestic transaction costs. ${ }^{18}$ These costs are assumed here to be exogenous represented by a monetary disutility $\psi(a)$ (while altering the recipient's development path) such that $\psi(0)=0, \psi^{\prime}(a)>0$ and $\psi^{\prime \prime}(a) \geq 0$. We also assume convexity of the marginal cost of avoided deforestation that is $\psi^{\prime \prime \prime}(a) \geq 0 .{ }^{19}$ Hence the recipient's gross surplus is then

$$
S(d, a, t)=u(d)+t-\psi(a)
$$

where $u(d)$ is the gross utility of deforestation for the recipient assumed to be strictly increasing $\left(u(0)=0, u^{\prime}(d)>0\right)$ and concave $\left(u^{\prime \prime}(d) \leq 0\right)^{20}$, and $t$ is a continuous choice variable that stands for the monetary transfer paid by the donor to the recipient in the REDD + scheme. However, outside the REDD + scheme, efforts are nil, ${ }^{21}$ so the recipient's outside option is $u(\theta-0)=u(\theta)$, such that $S(d, a, t) \geq u(\theta)$.

\footnotetext{
${ }^{17}$ From now on, in the model, we use mainly the word "deforestation" to refer to both "deforestation and forest degradation".

${ }^{18}$ Laing and Palmer (2015) show how these costs basically depend on general equilibrium effects and on lobbying efforts of national interest groups. These implementation and transaction costs could be in turn endogenized through the theory of incentives at a national level between a government and land-users because any actions that the government takes are likely to be exposed to free-riding behavior by parties within the country.

${ }^{19}$ This technical assumption means that the marginal cost is increasing, and the assumption avoids nonconvexities in the donor's optimization problem when information is asymmetric.

${ }^{20}$ Again, we assume that the technical assumption $u^{\prime \prime \prime}(d) \geq 0$ holds, to avoid non-convexities when information is asymmetric. This means that marginal utility must be convex.

${ }^{21}$ Indeed, if $t=0$, then $-u^{\prime}(\theta-a)-\psi^{\prime}(a)<0$, and the optimal actual domestic policies to avoid deforestation is clearly $a^{*}=0$.
} 
From the total remaining forest cover $\phi-d$, the donor derives a net surplus written as:

$$
W(d, t)=w(\phi-d)-t
$$

where $w(\cdot)$ is his gross utility, assumed to be strictly increasing and concave. ${ }^{22}$ These are three ways of considering the gross utility of the donor $w(\phi-d)$. First, the gross utility of the donor can be interpreted as the general preference for climate change mitigation because the donor is better off; more carbon can be sequestrated through less deforestation. Second, the gross utility of the donor can also be viewed as a more specific payoff derived from less deforestation because it allows carbon credits to be obtained (as with a Clean Development Mechanism (CDM)). In the latter case, for example, one could write $w(\phi-d)=p \times g(\phi-d)$, where $p$ would be the carbon price and $g(\cdot)$ an increasing function that allows carbon offsets. In that case, careful attention to the additionality issue is clearly required, as emphasized by Mason and Plantinga (2013). Third, one could also interpret the gross utility as built on an emission-based approach rather than a stock-based approach. Indeed, one could write $w(\phi-d)=v(\phi)-c(e(\phi-d))$ where $v(\phi)$ would be the forest amenities, including carbon already stored, and $c(e)$ the damage function increasing with carbon emissions $e$ which would be reduced by less deforestation in turns.

In the following, we do not consider that payments are based on results assessed against the RL but only on observable variables. Three types of mechanisms are considered to analyze our REDD+ schemes:

- A deforestation-based contract $(D C) C_{d} \equiv\langle t, d\rangle$ : monitoring efforts focus on actual deforestation and forest degradation (and not on actual domestic policies to reduce deforestation), which are therefore observable and contractible.

- A policy-based contract $(P C) C_{a} \equiv\langle t, a\rangle$ : monitoring efforts focus on observing actual domestic policies to avoid deforestation (and not on actual deforestation and forest degradation), which permits inclusion of them in the mechanism through conditionality.

- A general contract $(G C)$ which determines whether $C_{d}$ or $C_{a}$ must be proposed to the recipient.

As a benchmark and to clarify the issues involved, let us consider what would be the first-best REDD + mechanism for which information on the BAU baseline $\theta$ is common knowledge. This situation is what could happen if the BAU baselines were actually equal to the reference levels

\footnotetext{
${ }^{22}$ Since we do not address the political acceptability or the distributive issues in the North country when it finances such projects, there is no need to consider the marginal cost of public funds regarding the monetary transfer $t$.
} 
computed on the basis of the historical trend. In that case efforts and deforestation levels are observable and both the $D C$ and $P C$ are equivalent. In such a situation, the Principal the donor looks for a domestic policy to avoid deforestation $a$ that maximizes $W(d, t)$ :

$$
\max _{a, t} W(d, t) \quad \text { s.t. } \quad S(d, a, t) \geq u(\theta) \text { and } d=\theta-a
$$

The (participation) constraint directly implies a lower bound for the payment that is $t \geq u(\theta)-$ $u(\theta-a)+\psi(a)$ which is necessarily attained at the first-best since the scheme is costly for the donor. As a result, the first best avoided deforestation maximizes the overall surplus $W+U$ and so $a^{F B}(\theta)$ is the value of $a$ that obeys the marginal condition: ${ }^{23}$

$$
w^{\prime}(\phi-\theta+a)=u^{\prime}(\theta-a)+\psi^{\prime}(a)
$$

so that the deforestation level states $d^{F B}(\theta)=\theta-a^{F B}(\theta)$, and the payment $t^{F B}(\theta)$ is such that $U^{F B}=0$ : the donor can extract costlessly all of the recipient's net surplus. At this social optimum, avoided deforestation efforts balance the donor's marginal cost associated with the deforestation level $d$, i.e., $w^{\prime}(\phi-d)$, and the recipient's marginal benefit associated with the deforestation level $d$ involved in the REDD + scheme, i.e., $u^{\prime}(d)+\psi^{\prime}(a)$.

An important feature of the first-best outcome is that both $a^{F B}(\theta)$ and $d^{F B}(\theta)$ are increa$\operatorname{sing}^{24}$ with respect to $\theta$ : a higher BAU calls for a higher deforestation level for the recipient and also more stringent conditional policy. Another feature is that the monetary transfer is higher when the deforestation level is lower and when the domestic policy is set at a higher level.

\subsection{Countervailing incentives of the two possible contracts}

As underlined in previous sections, the information on BAU baselines cannot be considered as perfectly symmetric. As a result, with asymmetric information, the first-best contract is not optimal anymore because it can be manipulated by recipient countries. At their first-best levels, both possible contracts create opposite incentives for REDD + recipients. Whereas this kind of result is not new in the economic literature, it has never been emphasized in the context of REDD + contracts. These countervailing incentives are illustrated in an example in the following subsection; a rigorous proof is available in the Appendix.

\footnotetext{
${ }^{23}$ Moreover letting $a=\theta-d$, optimizing over $d$ yields the same result in this first-best setting.

${ }^{24}$ This is due to increasing differences in $(a, \theta)$ and $(d, \theta)$ for $W+U$. Indeed $\frac{\partial^{2}(W+U)}{\partial a \partial \theta}=-w^{\prime \prime}(\phi-\theta+a)-$ $u^{\prime \prime}(\theta-a)>0$ and $\frac{\partial^{2}(W+U)}{\partial d \partial \theta}=\psi^{\prime \prime}(\theta-d)>0$.
} 


\subsubsection{Incentives to mimic in a two-country example}

In this example, we provide a discretized version of our general framework where two countries have different BAU baselines. Both countries have the same initial forest cover $\phi=1000 \mathrm{~km}^{2}$. The low deforesting country is characterized by the intended baseline $\underline{\theta}=150 \mathrm{~km}^{2}$ and the high deforesting country by $\bar{\theta}=200 \mathrm{~km}^{2}$. Let us assume that $w(x)=x(2000-x)$ with $x=\phi-d$, $u(d)=d(400-d)$ and $\psi(a)=\frac{1}{2} a^{2}$. In this case, one can easily solve Eq.(1) and find that $d^{F B}(\theta)=\frac{1}{5} \theta+80$ and $a^{F B}(\theta)=\frac{4}{5} \theta-80$. Therefore the payment can be written as $t^{F B}(d)=$ $16(d-100)(150-d)$.

Table 1 illustrates how both countries will in turns mimic each other depending on the instrument offered (respectively $D C$ and $P C$ ). It shows the levels of deforestation $d$ and of avoided deforestation $a$ requested in the first-best contracts, as well as the levels of monetary transfer $t$ needed to ensure participation, and the rents that would be given (incentives to mimic).

\begin{tabular}{|l|l|l|c|}
\hline $\boldsymbol{D} \boldsymbol{C}$ & $d^{F B}$ & $t^{F B}$ & Incentives to mimic \\
\hline$\underline{\theta}=150$ & $\mathbf{1 1 0}$ & 6400 & $\mathbf{5 2 5 0}$ \\
\hline $\bar{\theta}=200$ & $\mathbf{1 2 0}$ & 9600 & -5750 \\
\hline
\end{tabular}

\begin{tabular}{|l|c|l|c|}
\hline $\boldsymbol{P C}$ & $a^{F B}$ & $t^{F B}$ & Incentives to mimic \\
\hline$\underline{\theta}=150$ & $\mathbf{4 0}$ & 6400 & -8000 \\
\hline $\bar{\theta}=200$ & $\mathbf{8 0}$ & 9600 & $\mathbf{4 0 0 0}$ \\
\hline
\end{tabular}

Table 1: First-best contracts and incentives to mimic for each country

For instance, if the low deforesting country faces a first-best $D C$ she would be invited to slow down her deforestation level to $110 \mathrm{~km}^{2}$ while receiving in return a payment of 6400 (in monetary units). Her net surplus would be zero by construction. However, if this low deforesting country would choose to slow down her deforestation level to $120 \mathrm{~km}^{2}$ or equivalently would communicate a $\mathrm{RL}$ of $200 \mathrm{~km}^{2}$ to the donor, she would receive in return a payment of 9600 while her net surplus for deforesting $200 \mathrm{~km}^{2}$ amounts to 4350 : she then obtains a rent of $9600-4350=5250$ which represents her incentives to mimic the high deforesting country when announcing her RL. The rent is earned from the recipient's informational advantage and it is called an informational rent. In some ways, this is the "cash" that must be given up to the recipient countries to dampen their rational incentives to distort the RL upward or downward according to the contractual scheme offered.

As depicted in Table 1, $D C$ create incentives to choose an excessive BAU baseline compared 
to the privately known BAU baseline because the associated transfer includes reimbursement of the total opportunity cost of the recipient, i.e., both the outside surplus and the cost of avoiding deforestation, which is increasing in the BAU baseline picked. This is exactly the case of the current REDD + mechanism. On the contrary, $P C$ create incentives to understate the BAU baseline level reported because the transfer includes reimbursement of the total opportunity reward of the recipient, i.e., the difference of the outside and inside gross surpluses, which is decreasing with the announcement.

Choosing a suitable instrument will induce some difficulties in the contract design for the donor and create countervailing incentives for a developing country. Consequently, a second-best REDD + mechanism has to be carefully designed to counterbalance all of these caveats. For the sake of clarity, the following subsections focus on the intuitions underlining the results; the mathematical proofs of the Propositions are provided in the Appendix.

\subsubsection{Second-best contracts under asymmetric information}

From now on, we aim to find how the optimal second-best $D C$ and $P C$ should be structured when the BAU baselines are not perfectly known by the donor. In that case, the $D C$ and $P C$ cannot be considered as equivalent anymore: as we have just seen, each scheme embodies different incentives for the developing country. The design of these contracts can be viewed as an application of the agency model under adverse selection analyzed in Laffont and Martimort (2002) for instance. Based on observable items only, these contracts make use of the revelation principle (Myerson (1979)) to lead the recipient country to reveal her private information about her true BAU baseline, or equivalently to pick the contract best suited to her type.

When the REDD + mechanism is built through a deforestation-based contract $(D C)$, both participation and incentive compatibility constraints must be verified. In the contract $C_{d}(\theta)=$ $\langle d(\theta), t(\theta)\rangle$, the recipient's participation must be ensured. This participation constraint implies that the recipient will sign the contract if she can obtain a net reward, a rent denoted $U(\theta)$, which is at least the one obtains with the first-best contract, i.e., zero. However, for incentive reasons, this rent shall be higher. Incentive compatibility implies that for all BAU baselines, the menu of contracts would be designed such that the developing country, as a recipient, will be better off selecting the contract corresponding to her true BAU baseline than another one and especially not a greater one. With our notations this implies that for $\theta, \hat{\theta}: U(\theta) \geq U(\theta, \hat{\theta})$, where $U(\theta, \hat{\theta})=S(d(\hat{\theta}), \theta-d(\hat{\theta}), t(\hat{\theta}))-u(\theta)$, is the net surplus of the recipient country with the true BAU baseline $\theta$ when choosing the contract $C_{d}(\hat{\theta})$. Considering differentiable contracts, 
this incentive compatibility constraints writes in a first-order manner:

$$
U^{\prime}(\theta)=-\psi^{\prime}(\theta-d(\theta))-u^{\prime}(\theta) \leq 0
$$

Eq. (2) shows how the net informational rent must be not increasing with $\theta$, to be incentive compatible. More precisely the way the rent decreases reflects the fact that, when a $D C$ is signed, the recipient incurs a marginal loss of an increase in her true BAU baseline. Indeed this marginal loss is composed by both a marginal increase of cost of avoiding deforestation due to the increase of the baseline and a marginal increase of outside surplus, which is an opportunity cost within the contract. Hence to tackle reference agreements regarding overstatement incentives $(\hat{\theta}>\theta)$ included in $D C$, the donor will have to give a higher information rent to low-deforesting countries than to high-deforesting ones. This is exactly what we have seen in the two-country example: as low-deforesting countries can obtain a rent mimicking high ones, the donor has to give up such a rent in order to propose a credible contract, while attempting to minimize it.

The optimality of $D C$ for the donor consists in maximizing his expected surplus taking into account both participation and incentive constraints. We now state a proposition that underlines the previous discussion and compares the $D C$ outcome with the first best.

Proposition 1 The REDD+ incentive compatible deforestation-based contract (DC) entails:

(i) a decreasing informational rent for the recipient when the BAU baseline $\theta$ increases;

(ii) more deforestation i.e., $d^{*}(\theta)>d^{F B}(\theta)$ and less resulting avoided deforestation, i.e., $\tilde{a}(\theta)=$ $\theta-d^{*}(\theta)<a^{F B}(\theta)$, than the first-best except for the lowest BAU baseline;

(iii) $d^{*}(\theta)$ the optimal deforestation level increases and $t_{d}^{*}(\theta)$ the REDD+ optimal transfer decreases with the BAU baseline $\theta$.

In line with the standard theory of incentives, the REDD $+D C$ implies a rent/efficiency tradeoff. Deforestation levels must be distorted upwards for any developing country (except the lowest BAU baseline) in order to minimize costly information rents. If the REDD + scheme promotes to decrease deforestation levels, the optimal deforestation-based scheme implies tackling forest areas where projected deforestation is per se the lowest. Consequently, information rents must be awarded to countries with lowest true deforestation BAU baselines to push them to the highest efficiency while coping with deforestation.

Second-best policy-based contracts When the REDD + mechanism is built through a policy-based contract $(P C)$ similar arguments as for the $D C$ hold. To ensure both participation 
of the recipient and incentive compatibility of the contract $C_{a}(\theta)=\langle a(\theta), t(\theta)\rangle$, an informational rent, now denoted $V(\theta)$ must be giving up by the donor. Participation implies again that the rent is non negative, $V(\theta) \geq 0$, but incentive compatibility differs and writes:

$$
V^{\prime}(\theta)=u^{\prime}(\theta-a(\theta))-u^{\prime}(\theta) \geq 0
$$

By concavity of $u(\cdot)$, we now see that the information rents must be not decreasing with $\theta$ to be incentive compatible. This is due to the fact that signing a $P C$ modifies the way the recipient evaluates an increase in her true BAU baseline. Indeed, she now earns a marginal reward composed by both a marginal increase of her gross utility of deforestation due to the increase of the baseline and a (weaker) marginal increase of outside surplus. Hence, to tackle reference agreements regarding understatement incentives included in $P C$, the donor will give a higher information rent to high-deforesting countries than to low-deforesting ones.

Proposition 2 The REDD+ incentive compatible policy-based scheme (PC) entails:

(i) an increasing informational rent for the recipient when the BAU baseline $\theta$ increases;

(ii) less avoided deforestation i.e., $a^{*}(\theta)<a^{F B}(\theta)$ and more resulting deforestation $\tilde{d}(\theta)=$ $\theta-a^{*}(\theta)>d^{F B}(\theta)$, than the first-best except for the highest BAU baseline;

(iii) $a^{*}(\theta)$ the optimal avoided deforestation level and $t_{a}^{*}(\theta)$ the REDD+ optimal transfer are strictly increasing at the margin with the BAU baseline $\theta$.

The rent/efficiency trade-off in the REDD $+P C$ acts in the opposite way relative to the $D C$ case. Avoided deforestation levels must be distorted downwards for any developing country to minimize costly information rents, except for the higher deforesting one. If the REDD + scheme promotes conditional deforestation levels, the optimal scheme implies tackling forest areas where intended deforestation is per se the highest. Consequently, information rents are awarded to forest areas with the highest $\mathrm{BAU}$ baseline order to encourage them to make the greatest effort to cope with deforestation.

Deforestation-based vs policy-based: what difference does it make? As analyzed previously, deforestation-based and policy-based contracts appear to have some opposite features. First of all, information rents vary in opposite directions with respect to the BAU baselines: deforestation-based schemes call for increasing the payments above the first-best level for lowdeforesting countries whereas policy-based schemes call for reducing them.

Second, to have more insights about the difference between both contracts we can compare both $D C$ and $P C$ outcomes by linking avoided and deforestation levels derived for both types 
of contracts. To state the comparison result, let us note $\tilde{\theta}$ the BAU baseline level for which the $D C$ optimal deforestation $d^{*}(\tilde{\theta})$ and the $P C$ resulting deforestation levels $\tilde{d}(\tilde{\theta})$ are equal. ${ }^{25}$

Proposition 3 For BAU baselines lower (resp. higher) than $\tilde{\theta}$, resulting outcomes, $\tilde{d}(\theta)$ and $\tilde{a}(\theta)$, are greater (resp. smaller) than the optimal ones for both $D C$ and $P C$.

Figure 2 provides an illustration of this result showing all optimal outcomes. The results in Proposition 3 show that REDD + contractual settings have also opposite effects on deforestation country's decisions depending on the BAU baseline. Indeed, for countries with a low projected deforesting activity, i.e., for weakly forest-dependent countries $(\theta<\tilde{\theta})$, as expected, $D C$ is more effective for coping with deforestation than $P C$. Therefore, the resulting avoided deforestation from $D C$ is greater than the corresponding one that $P C$ would recommend. On the contrary, for highly forest-dependent countries $(\theta>\tilde{\theta})$, the $D C$ will not reduce deforestation as much as $P C$ would. This is quite inconvenient because these countries could contribute more to reducing the carbon balance-sheets. As a result, the donor could be interested in mixing the two contractual forms in order to reduce deforestation further. For low BAU baselines, a $D C$ seems to be more effective than a $P C$. The opposite holds for high BAU baselines.

\section{Insert Figure 2}

\subsection{General contract: choosing between deforestation-based or policy-based contracts}

The previous discussion shows that there is a room for studying contractual arrangements that mix both contractual forms considered so far through a general contract $G C$ that will allow for choosing the best instrument between a deforestation-based $D C$ scheme and a policy-based $P C$ scheme. Indeed, the intuition seems to indicate that in order to reduce carbon emissions, a $D C$ contract is more effective than a $P C$ one for low BAU baselines and the opposite stands for high BAU baselines. However, mixing that way both contracts cannot be done without ensuring that the incentives are adequately aligned.

\subsubsection{Designing the general contract}

This kind of sophisticated contract design can be viewed as an application of Bontems and Bourgeon (2000) that analyze in a general manner the relative efficiency of output and input incentive schemes in an agency model under adverse selection. In our context, the output incentive scheme

\footnotetext{
${ }^{25}$ For the same value $\tilde{\theta}, a^{*}(\tilde{\theta})=\tilde{a}(\tilde{\theta})$.
} 
is the $D C$ (the output being the observed deforestation) and the input one the $P C$ (considering policy as input).

A general contract $G C$ can be written as $\left\langle C_{d}, C_{a}\right\rangle$ that determines whether respectively a $D C$ or a $P C$ scheme must be proposed to the Agent by the Principal. The difficulty in this case is that the Principal has to address countervailing incentives created by the contracting choice: how to conciliate the incentives to overstate the BAU baselines when a $D C$ is offered and the incentives to understate the BAU baselines for $P C$ ?

The following and last result shows that this is possible by reducing the informational rent for some medium BAU baseline, for which the first-best is optimal.

Proposition 4 There exists a medium value $\theta^{*} \in[\underline{\theta}, \bar{\theta}]$ of the BAU baseline such that below this value, the $D C$ is proposed, above this value, it is the PC. Optimal levels of deforestation $d^{*}(\theta)$ and avoided deforestation $a^{*}(\theta)$ remain defined by $D C$ and $P C$. Consequently, there are no distortions at the bottom and at the top. Finally for the medium BAU baseline $\theta^{*}$, the recipient's rent is zero.

Proposition 4 indicates that it is optimal for the donor to propose $D C$ to countries with the lowest true deforestation $\mathrm{BAU}$ baseline and to propose $P C$ to the countries with the highest deforestation BAU baselines. Offering the choice among different REDD + contracts creates countervailing incentives for the developing country that induce more efficiency for REDD+ scheme proposals. Indeed, dividing countries into two groups corresponding to two different based instruments helps the developed country to obtain deforestation and avoided deforestation levels closer to the first-best level. Moreover, this choice does not change the contract outcomes, that is deforestation and policy decisions that would be decided in each separate contracts. Finally, the donor can reduce all informational rents, which are necessarily given up to the contractors, by giving zero rent to a medium deforesting country.

The analysis of the $G C$ suggests that REDD+ deforestation-based contracts should be preferentially proposed to countries in the early stages of their forest transition, which are known to be characterized by high forest cover and low deforestation rates (Angelsen (2008a)). When the deforestation rate accelerates in later stages, policy-based contracts may be more adapted as REDD + mechanisms.

\subsubsection{General contract in an example}

In order to illustrate the contracting choice involved in the general contract, let us return to our leading example. Assume now that for any country that is involved in the REDD + scheme, the 
BAU baselines are known to be equiprobably distributed (i.e., as an uniform law so $f(\theta)=1 / 50$ ) over the range of $150 \mathrm{~km}^{2}$ to $200 \mathrm{~km}^{2}$. As a result, one can find that the $D C$ and $P C$ write now $d^{*}(\theta)=\frac{2}{5} \theta+50$ and $a^{*}(\theta)=\frac{6}{5} \theta-160$ and we represent them for some discretized values of the baselines. In Table 2 we present both contracts as if they were proposed separately where in Table 3, the general contract is depicted. Here the threshold baseline for which a switch of contractual form has to be done is about $175.5 \mathrm{~km}^{2}$. As we can see, the $G C$ helps reducing the rents allowed to all types of recipient in a substantial way.

\begin{tabular}{|l||c|c|c||c|c|}
\hline Baseline & $d^{F B}$ & $d^{*}$ & $\tilde{a}$ & Payment & Rents \\
\hline \hline 150 & 110 & $\mathbf{1 1 0}$ & 40 & 11650 & 5250 \\
\hline 160 & 112 & $\mathbf{1 1 4}$ & 46 & 10774 & 3920 \\
\hline 170 & 114 & $\mathbf{1 1 8}$ & 52 & 9906 & 2730 \\
\hline 180 & 116 & $\mathbf{1 2 2}$ & 58 & 9046 & 1680 \\
\hline 190 & 118 & $\mathbf{1 2 6}$ & 64 & 8194 & 770 \\
\hline 200 & 120 & $\mathbf{1 3 0}$ & 70 & 7350 & 0 \\
\hline
\end{tabular}

\begin{tabular}{|l||c|c|c|c|c|}
\hline Baseline & $a^{F B}$ & $a^{*}$ & $\tilde{d}$ & Payment & Rents \\
\hline \hline 150 & 40 & $\mathbf{2 0}$ & 130 & 2600 & 0 \\
\hline 160 & 48 & $\mathbf{3 2}$ & 128 & 4616 & 520 \\
\hline 170 & 56 & $\mathbf{4 4}$ & 126 & 6894 & 1280 \\
\hline 180 & 64 & $\mathbf{5 6}$ & 124 & 9224 & 2280 \\
\hline 190 & 72 & $\mathbf{6 8}$ & 122 & 11816 & 3520 \\
\hline 200 & 80 & $\mathbf{8 0}$ & 120 & 14600 & 5000 \\
\hline
\end{tabular}

Table 2: Deforestation-based and Policy-based Contracts in a single proposal

\begin{tabular}{|l|c|c|c|c|c|c|}
\hline Baseline & $d^{*}$ & $a^{*}$ & Contract & Payment & Rents & Reduction \\
\hline 150 & 110 & & Result & 9510.8 & 3110.8 & $40,7 \%$ \\
\hline 160 & 114 & & Result & 8634.8 & 1780.8 & $50.6 \%$ \\
\hline 170 & 118 & & Result & 7766.8 & 590.8 & $78.3 \%$ \\
\hline 180 & & 56 & Policy & 7849.5 & 483.5 & $78.8 \%$ \\
\hline 190 & & 68 & Policy & 9147.5 & 1723.5 & $51 \%$ \\
\hline 200 & & 80 & Policy & 10553.5 & 3203.5 & $35.9 \%$ \\
\hline
\end{tabular}

Table 3: General contract

In order to illustrate the environmental and financial gains that can be expected from the use of the general REDD + contract instead of the current REDD + , we can compute the expected levels of deforestation and rents. Considering that the current REDD + mechanism can be assimilated to the first best $D C$ contract when is plagued by inflated reports due to asymmetric information, then all countries have strong incentives to mimic the highest BAU and the expected level of deforestation reaches $\mathbb{E}(d)=120 \mathrm{~km}^{2}{ }^{26}$ Regarding $D C$ and $P C$ stand-alone incentive contracts, the expected deforestation levels increase to $\mathbb{E}\left(d^{*}\right)=120$ and $\mathbb{E}(\tilde{d})=125 \mathrm{~km}^{2}$ respectively. With the general combined contract, it is lowered to $\mathbb{E}\left(d^{G}\right)=$ $\int_{150}^{175.5} \frac{1}{50} d^{*}(\theta) d \theta+\int_{175.5}^{200} \frac{1}{50}\left(\theta-a^{*}(\theta)\right) d \theta=118.7 \mathrm{~km}^{2}$. As a result, deforestation is reduced on average.

\footnotetext{
${ }^{26}$ Note that if the first best contract was based on the domestic policy, the expected value of deforestation would be higher and stand to $135 \mathrm{~km}^{2}$.
} 
Considering the informational rents left by the donor to the recipient, the current REDD + scheme yields high average rents for the recipient $\mathbb{E}(U)=2416.6$ in monetary units. For $D C$ and $P C$ contracts, the expected rents are respectively reduced to $\mathbb{E}\left(U^{D C}\right)=2333.3$ and $\mathbb{E}\left(U^{P C}\right)=$ 2000. The $G C$ yields to $\mathbb{E}\left(U^{G}\right)=1480.5$.

Compared to the current REDD+ scheme, the combined $D C$ and $P C$ contracts in the $G C$ contract have the properties to reduce the average level of deforestation and to reduce the expected rent left to the recipient. Regarding $D C$ or $P C$ stand-alone incentive contracts, they have good financial features as rents are reduced, but they fail to succeed in environmental terms, as expected deforestation levels increase.

\section{Conclusion}

In this paper, we aimed to offer a theoretical analysis of an extended REDD + scheme in order to deal with potential information asymmetries that are inherent in the estimation of deforestation baselines required by the current scheme.

Our contribution can be summarized in three components. First, we show that assessing the performance of the contract against a RL constructed on the basis of the historical deforestation trend necessarily leads to reward some hot air for countries who would have, for different reasons, already followed a less-deforesting path than their historical trend. To overcome this shortage and reduce the informational rents, we propose to design incentive contracts exclusively based on observable variables, such as the deforestation level realized at the end of the contract. Second, we advocate that policy-based contracts may constitute a more powerful instrument than $e x$ post result-based payments for fragile countries who can be unable to fulfill their deforestation commitments by themselves. In that case, the contract should include an agreement on the definition and monitoring of the policy levers to be implemented by the recipient country to address the deforestation drivers. We have demonstrated that rewarding the recipient country, through non-linear payments either on observed deforestation or on monitored policy, reduces the rent left by the donor but increase the expected deforestation. Third, we propose to offer a general contract that may allow recipient countries to handle the choice of instruments with regard to their particular contexts. Our results strengthen the case of conditionality-based contracts (in the sense of Karsenty and Ongolo (2012)) but only for the developing countries with the highest intended deforestation BAU baseline, which is not strictly equivalent to their historical trend. For countries still picking deforestation-based contracts, we have proved that instead of using an 
extrapolation of their historical deforestation trend as a RL, a simple non-linear transfer would permit revelation of the projected BAU baseline of the country and reduce both the excessive deforestation allowed by the current REDD + contracts and the information rent granted to the deforesting countries.

The emergence of legitimate rents for recipients built on an informational base is a key feature of the Principal-Agent approach we adopt to analyze $D C$ or $P C$ REDD + schemes. Nevertheless, other issues related to performance-based payments may distort the level and the strength of these rents. For instance in our general contract, high rents may be awarded to countries with low or high BAU baselines at the end of the contract in return for low deforestation rates during the commitment period. This is indeed optimal if the donor's credibility in being tough, mainly with medium BAU baselines recipients, is sufficiently strong, which is actually the case in our approach since the donor, acting as a Principal, is assumed to hold all bargaining power. However, some doubts about this credibility have been highlighted in the literature, but, as explained in Angelsen (2017), the authority for disbursement is more and more handed over to third parties as the World Bank for example or through multinational programs which clearly has an increasing effect in the credibility of the donation process.

Another issue that could dampen the effectiveness of the rents distribution is that resultbased schemes put all external risk on the recipient. Indeed, avoided deforestation and forest degradation may cause recipients to bear uncertain costs due to radical changes in the structure of the agricultural income. In some sense, this causes an increase in the outside opportunity expected gains from not participating to REDD + programs. To take this issue into account, the donor could raise ex ante the payments by incorporating a risk premium.

A last issue is that all parties involved in REDD + contracts may be capital-constrained. Low income recipients may have financial difficulties to engage in costly actions during the commitment period, whereas they will be rewarded only at the end of the contract. To circumvent this obstacle, one could imagine that in case of deforestation-based contract, the donor could also act as a lender that would clear the debt at the end of the contract (at the expense of an additional moral hazard issue), whereas in the policy-based contract, the fundings could be paid in successive tranches contingent on progress in achieving policy reforms. 


\section{Appendix: proofs}

Proof of Countervailing Incentives: We show here that the first-best contract is not optimal if $\theta$ is private information for the recipient. Indeed reporting to the donor a baseline $\hat{\theta}$ instead of $\theta$, leads to a net information rent $U(\theta, \hat{\theta})$ depending on whether the deforestation level $d^{F B}(\theta)$ or the domestic efforts to avoid deforestation $a^{F B}(\theta)$ is really applied by the Agent once she has signed the contract. Starting from the FB contract menu of (equivalent) contracts $\left\langle d^{F B}(\hat{\theta}), t^{F B}(\hat{\theta})\right\rangle_{\hat{\theta} \in \Theta}$ or $\left\langle a^{F B}(\hat{\theta}), t^{F B}(\hat{\theta})\right\rangle_{\hat{\theta} \in \Theta}$ if the Agent chooses to apply $d^{F B}(\hat{\theta})$ in the contract (that is the real effort will be $\left.a(\theta, \hat{\theta})=\theta-d^{F B}(\hat{\theta})\right)$ then

$$
U(\theta, \hat{\theta})=u\left(d^{F B}(\hat{\theta})\right)-\psi\left(\theta-d^{F B}(\hat{\theta})\right)-u(\theta)+\psi\left(a^{F B}(\hat{\theta})\right)+u(\hat{\theta})-u\left(d^{F B}(\hat{\theta})\right)
$$

which is increasing if $\hat{\theta}=\theta$ as $U_{\hat{\theta}}^{\prime}(\theta, \hat{\theta})=d^{F B^{\prime}}(\hat{\theta}) \psi^{\prime}\left(\theta-d^{F B}(\hat{\theta})\right)+a^{F B^{\prime}}(\hat{\theta}) \psi^{\prime}\left(a^{F B}(\hat{\theta})\right)+u^{\prime}(\hat{\theta})$ so $U_{\hat{\theta}}^{\prime}(\theta, \theta)=\psi^{\prime}\left(a^{F B}(\theta)\right)+u^{\prime}(\theta)>0$. As a result, deforesting Agents are likely to overstate their baseline announcement $(\hat{\theta}>\theta)$. However if the Agent chooses to apply $a^{F B}(\hat{\theta})$ (then $\left.d(\theta, \hat{\theta})=\theta-a^{F B}(\hat{\theta})\right)$ then

$$
U(\theta, \hat{\theta})=u\left(\theta-a^{F B}(\hat{\theta})\right)-\psi\left(a^{F B}(\hat{\theta})\right)-u(\theta)+\psi\left(a^{F B}(\hat{\theta})\right)+u(\hat{\theta})-u\left(d^{F B}(\hat{\theta})\right)
$$

which is decreasing if $\hat{\theta}=\theta$ as $U_{\hat{\theta}}^{\prime}(\theta, \hat{\theta})=-a^{F B^{\prime}}(\hat{\theta})\left[u\left(\theta-a^{F B}(\hat{\theta})\right)-u^{\prime}\left(d^{F B}(\hat{\theta})\right)\right]+u^{\prime}(\hat{\theta})-$ $u^{\prime}\left(d^{F B}(\hat{\theta})\right)$, so $U_{\hat{\theta}}^{\prime}(\theta, \theta)=u^{\prime}(\theta)-u^{\prime}\left(d^{F B}(\theta)\right)<0$ since $u^{\prime}(\cdot)$ is decreasing and $\theta \geq d^{F B}(\theta)$. As a result, Agents are likely to understate their baseline announcement $(\hat{\theta}<\theta)$.

Proof of Proposition 1: The techniques developed for assessing the $D C$ contract can be viewed as adaptations of the standard Principal-Agent model with adverse selection (see Laffont and Martimort (2002) among others), consequently we just mention the main features of the analysis. First, local incentive compatibility ensures here global incentive compatibility of the contract as the so-called Single Crossing or Spence-Mirrlees property is verified as $\partial^{2} U / \partial d \partial \theta=$ $-\psi^{\prime \prime}(\theta-d(\theta))<0$ has a constant sign. The first order incentive compatibility constraint implies $U(\theta) \geq U(\theta, \hat{\theta})$ or equivalently $\partial U(\theta, \hat{\theta}) / \partial \hat{\theta}=0$ implying in turns that $U^{\prime}(\theta)=\partial U(\theta, \theta) / \partial \theta$, that is Eq. (2) in the text. The local second order incentives $d^{\prime}(\theta) \geq 0$ is sufficient, since it must be true that $\partial^{2} U(\theta, \theta) / \partial \hat{\theta} \partial \theta=\psi^{\prime \prime}(\theta-d(\theta)) d^{\prime}(\theta) \geq 0$. The expected net donor's surplus writes as $E_{d}(W)=\int_{\underline{\theta}}^{\bar{\theta}}[w(\phi-d(\theta))-t(\theta)] f(\theta) d \theta$ where the transfer $t(\theta)=U(\theta)+\psi(\theta-d(\theta))+$ $u(\theta)-u(d(\theta))$ and $U(\theta)$ is the rent.

Second, in order to solve $\max _{C_{d}(\theta)} E_{d}(W)$ s.t. $U^{\prime}(\theta) \leq 0$ and $d^{\prime}(\theta) \geq 0$, we substitute $t(\theta)$ 
and include the expected information rent (after by parts integration), which leads to donor's decision program:

$$
\begin{gathered}
\max _{d(\theta), U(\bar{\theta})} \int_{\underline{\theta}}^{\bar{\theta}}\{w(\phi-d(\theta))-[u(\theta)-u(d(\theta))+\psi(\theta-d(\theta))] \\
\left.-\left[\psi^{\prime}(\theta-d(\theta))+u^{\prime}(\theta)\right] \varphi(\theta)\right\} f(\theta) d \theta-U(\bar{\theta}) \\
\text { s.t. } U(\bar{\theta}) \geq 0 \text { and } d^{\prime}(\theta) \geq 0
\end{gathered}
$$

This leads to the following first-order condition that defines the second-best deforestation level $d^{*}(\theta)$ as the value of $d$ such that:

$$
w^{\prime}(\phi-d)=u^{\prime}(d)+\psi^{\prime}(\theta-d)+\psi^{\prime \prime}(\theta-d) \varphi(\theta)
$$

where $\varphi(\theta)=F(\theta) / f(\theta)$ is known as the hazard rate of the prior belief $F(\theta)$, which is increasing because the latter has been considered log-concave. From its linearity in $U(\bar{\theta})$, we also derive that $U^{*}(\bar{\theta})=0$. Differentiating (4) with respect to $\theta$, verifies the second order incentive compatibility condition: $d^{\prime}(\theta) \geq 0$. Indeed as $\psi^{\prime \prime \prime} \geq 0$ :

$$
d^{* \prime}(\theta)=\frac{\psi^{\prime \prime}\left(\theta-d^{*}\right)\left[1+\varphi^{\prime}(\theta)\right]+\psi^{\prime \prime \prime}\left(\theta-d^{*}\right) \varphi(\theta)}{\psi^{\prime \prime}\left(\theta-d^{*}\right)+\psi^{\prime \prime \prime}\left(\theta-d^{*}\right) \varphi(\theta)-w^{\prime \prime}\left(\phi-d^{*}\right)-u^{\prime \prime}\left(d^{*}\right)} \geq 0
$$

$d^{*}(\theta)$ is increasing at the margin with the BAU baseline.

Third, studying $d^{*}(\theta)$ as the implicit continuous solution in (4) shows that $d^{*}(\theta) \geq d^{F B}(\theta)$. Indeed let $\omega(d)=w(\phi-d)-[\psi(\theta-d)-u(d)]$ a concave function of $d$, then we have, for all $\theta, \omega^{\prime}\left(d^{*}\right)=-\psi^{\prime \prime}\left(\theta-d^{*}\right) \varphi(\theta) \leq 0=\omega^{\prime}\left(d^{F B}\right)$. This yields the result, since $\omega^{\prime}(d)$ is decreasing. As $\varphi(\underline{\theta})=0$, the no distortion at the bottom result follows easily: $d^{*}(\underline{\theta})=d^{F B}(\underline{\theta})$. Hence defining $\tilde{a}(\theta)=\theta-d^{*}(\theta)$, as $d^{*}(\theta) \geq d^{F B}(\theta)$ then $\tilde{a}(\theta) \leq \theta-d^{F B}(\theta)=a^{F B}(\theta)$, with equality for $\theta=\underline{\theta}$.

Finally, The optimal transfer $t_{d}^{*}(\theta)$ can be stated as follows $t_{d}^{*}(\theta)=U^{*}(\theta)-u\left(d^{*}\right)+\psi(\theta-$ $\left.d^{*}(\theta)\right)+u(\theta)$ so that $t_{d}^{* \prime}(\theta)=-\left[u^{\prime}\left(d^{*}\right)+\psi^{\prime}\left(\theta-d^{*}(\theta)\right)\right] d^{\prime}(\theta)<0$ which proves that it is decreasing with the BAU baseline. This ends the proof of Proposition 1.

Proof of Proposition 2: With a $P C$ contract the expected net surplus of the donor writes now $E_{a}(W)=\int_{\underline{\theta}}^{\bar{\theta}}[w(\phi-\theta+a(\theta))-t(\theta)] f(\theta) d \theta$ where the transfer is defined by $t(\theta)=V(\theta)+$ $\psi(a(\theta))+u(\theta)-u(\theta-a(\theta))$ and the rent is $V(\theta)$. Again, the donor problem is to determine $C_{a}(\theta)$ to maximize $E_{a}(W)$ taking into account the participation $V(\theta) \geq 0$ and incentive compatibility constraints. With a $P C$ contract the first order incentive compatibility constraint implies $V(\theta) \geq$ $V(\theta, \hat{\theta})$ that is Eq. (3) in the text. Spence-Mirrlees property is also verified as $\partial^{2} V / \partial a \partial \theta=$ 
$-u^{\prime \prime}(\theta-a(\theta))<0$ has a constant sign. So the local second-order incentives imply that $a^{\prime}(\theta) \geq$ 0 , because it must now be verified that $\partial^{2} V(\theta, \theta) / \partial \hat{\theta} \partial \theta=-a^{\prime}(\theta) u^{\prime \prime}(\cdot) \geq 0$. That is, the policy decision does not decrease with the BAU baseline. The donor's problem is now to solve $\max _{C_{a}(\theta)} E_{a}(W)$ s.t. $V^{\prime}(\theta) \geq 0$ and $a^{\prime}(\theta) \geq 0$, which can also be written as

$$
\begin{aligned}
& \max _{a(\theta), V(\underline{\theta})} \int_{\underline{\theta}}^{\bar{\theta}}\{w(\phi-\theta+a(\theta))-[u(\theta)-u(\theta-a(\theta))+\psi(a(\theta))] \\
& \left.-\left[u^{\prime}(\theta-a(\theta))-u^{\prime}(\theta)\right] \bar{\varphi}(\theta)\right\} f(\theta) d \theta-V(\underline{\theta}) \\
& \text { s.t. } V(\underline{\theta}) \geq 0 \text { and } a^{\prime}(\theta) \geq 0
\end{aligned}
$$

By solving it, one can state the optimal avoided deforestation $a^{*}(\theta)$ as the value of $a$ such that:

$$
w^{\prime}(\phi-\theta+a)=u^{\prime}(\theta-a)+\psi^{\prime}(a)-u^{\prime \prime}(\theta-a) \bar{\varphi}(\theta)
$$

where $\bar{\varphi}(\theta)=(1-F(\theta)) / f(\theta)$ is the hazard rate of the prior belief $1-F(\theta)$; it is decreasing in $\theta$. The solution $V^{*}(\underline{\theta})=0$ comes again from the linearity of the objective in $V(\underline{\theta})$. Studying $a^{*}(\theta)$ as the implicit continuous solution in (5) shows that $a^{*}(\theta) \leq a^{F B}(\theta)$. Indeed let $\hat{\omega}(a, \theta)=$ $w(\phi-\theta+a)-[\psi(a)-u(\theta-a)]$ a concave function of $a$, then we have:

$$
\hat{\omega}_{a}^{\prime}\left(a^{*}, \theta\right)=-u^{\prime \prime}\left(\theta-a^{*}\right) \bar{\varphi}(\theta) \geq 0=\hat{\omega}_{a}^{\prime}\left(a^{F B}, \theta\right)
$$

for all $\theta$ so $a^{*}(\theta) \leq a^{F B}(\theta)$ as $\hat{\omega}_{a}^{\prime}(a, \theta)$ is decreasing. Equality holds at $\theta=\bar{\theta}$ as $\varphi(\bar{\theta})=0$, i.e., there is no distortion at the top : $a^{*}(\bar{\theta})=a^{F B}(\bar{\theta})$. Differentiating implicitly (5) with respect to $\theta$, shows that the second order incentive compatibility condition is verified:

$$
a^{* \prime}(\theta)=\frac{\left[u^{\prime \prime \prime}\left(\theta-a^{*}\right) \bar{\varphi}(\theta)-u^{\prime \prime}\left(\theta-a^{*}\right)\left(1-\bar{\varphi}^{\prime}(\theta)\right)\right]-w^{\prime \prime}\left(\phi-\theta+a^{*}\right)}{\left[u^{\prime \prime \prime}\left(\theta-a^{*}\right) \bar{\varphi}(\theta)+\psi^{\prime \prime}\left(a^{*}\right)-u^{\prime \prime}\left(\theta-a^{*}\right)\right]-w^{\prime \prime}\left(\phi-\theta+a^{*}\right)} \geq 0
$$

$a^{*}$ is increasing at the margin with the BAU baseline.

Finally, the optimal transfer $t_{a}^{*}(\theta)$ writes $t_{a}^{*}(\theta)=V^{*}(\theta)-u\left(\theta-a^{*}(\theta)\right)+\psi\left(a^{*}(\theta)\right)+u(\theta)$ and this yields $t_{a}^{* \prime}(\theta)=\left[u^{\prime}\left(\theta-a^{*}(\theta)\right)+\psi^{\prime}\left(a^{*}(\theta)\right)\right] a^{\prime}(\theta)>0$; so it is increasing with the BAU baseline.

Proof of Proposition 3: From Propositions 1 and 2 we know first that $d^{*}(\underline{\theta})=d^{F B}(\underline{\theta})=$ $\underline{\theta}-a^{F B}(\underline{\theta})$ and $a^{*}(\bar{\theta})=a^{F B}(\bar{\theta})=\bar{\theta}-d^{F B}(\bar{\theta})$. Both functions $d^{*}(\theta)$ and $a^{*}(\theta)$ are continuous in $\theta$, so are the corresponding resulting levels $\tilde{a}(\theta)=\theta-d^{*}(\theta)$ and $\tilde{d}(\theta)=\theta-a^{*}(\theta)$. Let us denote the difference $\Delta(\theta)=a^{*}(\theta)-\tilde{a}(\theta)$, a continuous function from $[\underline{\theta}, \bar{\theta}]$ onto $\mathbb{R}$, which 
has also the direct property that $\Delta(\theta)=d^{*}(\theta)-\tilde{d}(\theta)$. Moreover $\Delta(\underline{\theta})=a^{*}(\underline{\theta})-a^{F B}(\underline{\theta})<$ $0<\Delta(\bar{\theta})=d^{*}(\bar{\theta})-d^{F B}(\bar{\theta})$. Invoking the Intermediate Value theorem, we know it exists at least one $\tilde{\theta}$ in $] \underline{\theta}, \bar{\theta}[$ such that $\Delta(\tilde{\theta})=0$. Now let us denote $\tilde{\Theta}=\{\theta \in[\underline{\theta}, \bar{\theta}] \mid \Delta(\theta)=0\}$, hence $\tilde{\Theta} \neq \varnothing$. By construction, if $\theta<\inf \tilde{\Theta}, \Delta(\theta)$ have a constant sign, the one had for $\theta=\underline{\theta}^{+}$, hence $\Delta(\theta)<0$, i.e., the reverse is true for $\theta>\sup \tilde{\Theta}$.

Proof of Proposition 4: We define a GC that is $C(\theta)=\left\langle C_{d}(\theta), C_{a}(\theta), \rho(\theta)\right\rangle$ for all $\theta$, in which $C_{d}(\theta)$ and $C_{a}(\theta)$ are the REDD + schemes that we studied above; $C_{d}(\theta)$ stands for DC and $C_{a}(\theta)$ stands for PC. $\rho(\theta) \in\{0,1\}$ is a binary decision variable such that $\rho(\theta)=0$ if the contract offered is $C_{d}(\theta)$ and $\rho(\theta)=1$ if the contract offered is $C_{a}(\theta)$. It is not certain ex ante that optimal levels of transfers and actions achieved in the GC will be exactly the same as in the separate contracts studied in Sections previously. In that case the net informational rent of the developing country in the PC is written as $Y(\theta)=\rho(\theta) V(\theta)+(1-\rho(\theta)) U(\theta)$ and the incentive compatibility constraints are now written as

$$
Y^{\prime}(\theta)=\rho(\theta) V^{\prime}(\theta)+(1-\rho(\theta)) U^{\prime}(\theta)=\rho(\theta) u^{\prime}(\theta-a(\theta))-(1-\rho(\theta)) \psi^{\prime}(\theta-d(\theta))-u^{\prime}(\theta
$$

together with $a^{\prime}(\theta) \geq 0$ and $d^{\prime}(\theta) \geq 0$. They are simply a mix of incentive compatibility constraints in both underlying contracts. Participation constraints are now given by $Y(\theta) \geq 0$ for all $\theta$, and the donor's problem is to determine $C(\theta)$ to maximize his expected net surplus, which is written as

$$
E(W)=\int_{\underline{\theta}}^{\bar{\theta}}\{\rho(\theta) \hat{\omega}(a(\theta), \theta)+(1-\rho(\theta)) \omega(d(\theta))-[Y(\theta)+u(\theta)]\} f(\theta) d
$$

where $\omega(d)=w(\phi-d)-[\psi(\theta-d)-u(d)]$ and $\hat{\omega}(a, \theta)=w(\phi-\theta+a)-[\psi(a)-u(\theta-a)]$.

In order to prove Proposition 4, we show that results in Bontems and Bourgeon (2000), hereafter BB, can apply in our specific context, and more precisely their Proposition 7 (p.195). First, we show that our model can be rewritten in order to match with their assumptions and notations. Let the following change of variable in order to fit their modelling, $\tau=z-\theta \in[\underline{\theta}, \bar{\theta}]$ where $\theta \in[\underline{\theta}, \bar{\theta}]$ is still our BAU baseline variable; $\tau$ is the adverse selection variable in $\mathrm{BB}$ and where $z=\bar{\theta}+\underline{\theta}$. Hence one can write that production function in $\mathrm{BB}$ becomes $Q(a, \tau)=$ $\phi+\tau+a-z$. A slight difference between our setting and that of BB, is that the Principal's surplus $w(q)$ is nonlinear in $q \equiv \phi-d$, but as it is strictly increasing in $q$, this has a light impact on the results. The required properties on the production function have to be verified in our setting on the Principal's surplus: $\partial_{a} w(Q(a, \tau))=w^{\prime}(Q(a, \tau))>0$ and $\partial_{\tau} w(Q(a, \tau))=$ 
$w^{\prime}(Q(a, \tau))>0$. Moreover, in BB the Agent utility is defined by $U=t-\mathcal{V}(a, \tau)$ where in our context $\mathcal{V}(a, \tau)=\psi(a)+u(z-\tau)-u(z-\tau-a)$. We now check that the required properties of $V(a, \tau)$ in BB hold in our model: i) $\mathcal{V}(a, \tau)>0$; ii) $\partial_{a} \mathcal{V}(a, \tau)=\psi^{\prime}(a)+u^{\prime}(z-\tau-a)>0$ ; iii) $\partial_{a a} \mathcal{V}(a, \tau)=\psi^{\prime \prime}(a)-u^{\prime \prime}(z-\tau-a)>0$; iv) $\partial_{\tau} \mathcal{V}(a, \tau)=u^{\prime}(z-\tau-a)-u^{\prime}(z-\tau)>0$ (by concavity of $u$ ) ; v) $\partial_{a \tau} \mathcal{V}(a, \tau)=-u^{\prime \prime}(z-\tau-a)>0$. In BB, results depend on a difference between hypothetical marginal rates of substitution of efforts $\Delta(a, \tau)=\frac{\partial_{\tau} Q(a, \tau)}{\partial_{a} Q(a, \tau)}-\frac{\partial_{\tau} \mathcal{V}(a, \tau)}{\partial_{a} \mathcal{V}(a, \tau)}$ which equals here:

$$
\Delta(a, \tau)=\frac{\psi^{\prime}(a)+u^{\prime}(z-\tau)}{\psi^{\prime}(a)+u^{\prime}(z-\tau-a)}>0
$$

As $\Delta(a, \tau)$ turns out to be positive, this implies that a type-dependent contract might be proposed. Some conditions are also imposed on $\Delta(a, \tau): \mathrm{R} 1) \Delta(a, \tau)$ has a constant sign, which is true here (Spence-Mirrlees condition); R2) $\partial_{a}\left[\partial_{a} \mathcal{V}(a, \tau) \Delta(a, \tau)\right]=\psi^{\prime \prime}(a)>0$. A last condition is imposed in the BB model (namely R3) that is verified in our setting, is that economic fundamentals $(\mathcal{V}, F, w, Q)$ allow separating optimal contracts when the Principal restricts herself using the same instrument for all Agents, which is verified as shown in Propositions 1 and 2. Now it remains to invoke Proposition 7 in $\mathrm{BB}$, that shows that it exists $\tau^{*}$ defined by:

$$
\begin{aligned}
& w\left(Q\left(a^{*}\left(\tau^{*}\right), \tau^{*}\right)\right)-\mathcal{V}\left(a^{*}\left(\tau^{*}\right), \tau^{*}\right)-\partial_{\tau} \mathcal{V}\left(a^{*}\left(\tau^{*}\right), \tau^{*}\right) \frac{F\left(\tau^{*}\right)}{f\left(\tau^{*}\right)} \\
= & w\left(d^{*}\left(\tau^{*}\right)\right)-\mathcal{V}\left(\tilde{a}\left(\tau^{*}\right), \tau^{*}\right)-\partial_{a} \mathcal{V}\left(\tilde{a}\left(\tau^{*}\right), \tau^{*}\right) \Delta\left(\tilde{a}\left(\tau^{*}\right), \tau^{*}\right) \frac{1-F\left(\tau^{*}\right)}{f\left(\tau^{*}\right)}
\end{aligned}
$$

These previous relations can be rewritten as

$\hat{\omega}\left(a^{*}\left(\tau^{*}\right), \tau^{*}\right)-\partial_{\tau} \mathcal{V}\left(a^{*}\left(\tau^{*}\right), \tau^{*}\right) \frac{F\left(\tau^{*}\right)}{f\left(\tau^{*}\right)}=\omega\left(d^{*}\left(\tau^{*}\right)\right)-\partial_{a} \mathcal{V}\left(\tilde{a}\left(\tau^{*}\right), \tau^{*}\right) \Delta\left(\tilde{a}\left(\tau^{*}\right), \tau^{*}\right) \frac{1-F\left(\tau^{*}\right)}{f\left(\tau^{*}\right)}$

Substituting relevant terms, this gives:

$$
\begin{aligned}
& \hat{\omega}\left(a^{*}\left(\tau^{*}\right), \tau^{*}\right)-\left[u^{\prime}\left(z-\tau^{*}-a^{*}\right)-u^{\prime}\left(z-\tau^{*}\right)\right] \frac{F\left(\tau^{*}\right)}{f\left(\tau^{*}\right)} \\
& =\omega\left(d^{*}\left(\tau^{*}\right)\right)-\left[\psi^{\prime}\left(z-\tau^{*}-d^{*}\left(\tau^{*}\right)\right)+u^{\prime}\left(d^{*}\left(\tau^{*}\right)\right)\right] \frac{\psi^{\prime}\left(z-\tau^{*}-d^{*}\left(\tau^{*}\right)\right)+u^{\prime}\left(z-\tau^{*}\right)}{\psi^{\prime}\left(z-\tau^{*}-d^{*}\left(\tau^{*}\right)\right)+u^{\prime}\left(d^{*}\left(\tau^{*}\right)\right)} \frac{1-F\left(\tau^{*}\right)}{f\left(\tau^{*}\right)}
\end{aligned}
$$

Taking into account the initial change of variable and the fact that $F(\tau)=1-F(\theta) ; d F(\tau)=$ $-d F(\theta)$ so that $f(\tau) d \tau=-f(\theta) d \theta$ but since $\frac{d \tau}{d \theta}=-1$ then $f(\tau)=f(\theta)$, it implies that $\frac{F\left(\tau^{*}\right)}{f\left(\tau^{*}\right)}=\frac{1-F\left(\theta^{*}\right)}{f\left(\theta^{*}\right)}=\bar{\varphi}\left(\theta^{*}\right)$ and that $\frac{1-F\left(\tau^{*}\right)}{f\left(\tau^{*}\right)}=\frac{F\left(\theta^{*}\right)}{f\left(\theta^{*}\right)}=\varphi\left(\theta^{*}\right)$. Hence $\theta^{*}$ is defined by the 
equation:

$$
\omega\left(d^{*}\right)-\left[\psi^{\prime}\left(\theta^{*}-d^{*}\right)+u^{\prime}\left(\theta^{*}\right)\right] \varphi\left(\theta^{*}\right)=\hat{\omega}\left(a^{*}, \theta^{*}\right)-\left[u^{\prime}\left(\theta^{*}-a^{*}\right)-u^{\prime}\left(\theta^{*}\right)\right] \bar{\varphi}\left(\theta^{*}\right)
$$

As we have seen above, condition R2 holds so appying the Corollary 6 in BB yields to $Y\left(\theta^{*}\right)=0$, that is for $\theta^{*}$, the recipient's rent is zero. This completes the proof of Proposition 4.

\section{References}

[1] Alston L.J. and Andersson K., 2011. Reducing Greenhouse Gas Emissions by Forest Protection: The Transaction Costs of Implementing REDD. Climate Law. 2(2), 281-289.

[2] Angelsen A., 2008a. REDD Models and Baselines. International Forestry Review. 10(3), $465-475$.

[3] Angelsen A., 2008b. How Do We Set the Reference Levels for REDD Payments? In Angelsen, A. (ed.), Moving Ahead with REDD: Issues, Options and Implications. Bogor: CIFOR. $53-64$.

[4] Angelsen A., 2010. The 3 REDD "I" s (Editorial). Journal of Forest Economics. 16, 253-256.

[5] Angelsen A., 2017. REDD + as Result-based Aid: General Lessons and Bilateral Agreements of Norway. Review of Development Economics.21(2), 237-264.

[6] Azam, J.-P. and Laffont J.-J., 2003. Contracting for Aid. Journal of Development Economics. $70(1), 25-58$.

[7] Bontems P. and Bourgeon J.-M., 2000. Creating Countervailing Incentives Through the Choice of Instruments. Journal of Public Economics. 76, 181-202.

[8] Busch J., Lubowski R.N., Godoy F., Steininger M., Yusuf A.A., Austin K., Hewson J., Juhn D., Muhammad F. and Boltz F., 2012. Structuring Economic Incentives to Reduce Emissions from Deforestation within Indonesia. Proceedings of the National Academy of Sciences (PNAS). 109(4), 1062-1067.

[9] Chagas T., Costenbader J., Streck C. and Roe S., 2013. Reference Levels: Concepts, Functions, and Application in REDD+ and Forest Carbon Standards. Climate Focus, Amsterdam.

[10] Collier P., Guillaumont P., Guillaumont S. and Gunning J.W., 1997. Redesigning Conditionality. World Development. 25(9), 1399-1407. 
[11] Combes-Motel P., Pirard R. and Combes J.-L., 2009. A Methodology to Estimate Impacts of Domestic Policies on Deforestation: Compensated Successful Efforts for "Avoided Deforestation" (REDD). Ecological Economics. 68(3), 680-691.

[12] Cordero-Salas P. and Roe B.E., 2012. The Role of Cooperation and Reciprocity in Structuring Carbon Sequestration Contracts in Developing Countries American Journal of Agricultural Economics. 82, 389-399.

[13] Cordero-Salas P., Sohngen B. and Roe B.E., 2016. Additionality when REDD Contracts must be Self-Enforcing Environmental \&3 Resource Economics, DOI 10.1007/s10640-016$0072-9$

[14] Drazen A., 2012. Conditionality and Ownership in IMF Lending: A Political Economy Approach, IMF Staff Papers, 49, 36-67.

[15] Ekins P., Kesicki F. and Smith A.Z.P., 2011. Marginal Abatement Costs Curves: A Call for Caution. London, UK: University College London.

[16] Eliasch J., 2008. Climate Change: Financing Global Forests: the Eliasch review. Earthscan.

[17] Food and Agriculture Organization of the United Nations (FAO), 2014. Emerging Approaches to Forest Reference Emission Levels and/or Forest Reference Levels for REDD+, UN-REDD Programme.

[18] Gregersen H., El Lakany H., Karsenty A. and White A., 2010. Does the Opportunity Cost Approach Indicate the Real Cost of REDD+? Rights and Realities of Paying for REDD+. Rights and Resources Initiative, Washington, DC.

[19] Guesnerie R. and Laffont J.-J., 1984. A Complete Solution to a Class of Principal Agent Problems with an Application to the Control of a Self-Managed Firm. Journal of Public Economics. 25(3), 329-369.

[20] Heal G. and Conrad K., 2006. Incentive to Reduce Tropical Deforestation (Editorial). Journal of Forest Economics. 11, 201-203.

[21] Horowitz J. K. and Just R. E., 2013. Economics of Additionality for Environmental Services from Agriculture. Journal of Environmental Economics and Management. 66(1), 105-122. 
[22] Huettner M., Leemans R., Kok K. and Ebeling J., 2009. A Comparison of Baseline Methodologies for "Reducing Emissions from Deforestation and Degradation". Carbon Balance and Management. 4(4).

[23] Intergovernmental Panel on Climate Change (IPCC), 2014. Climate Change 2014-Impacts, Adaptation and Vulnerability: Regional Aspects. Cambridge University Press, Cambridge.

[24] Irland L.C., 2008. State Failure, Corruption, and Warfare: Challenges for Forest Policy. Journal of Sustainable Forestry. 27(3), 189-223.

[25] Karsenty A. and Ongolo S., 2012. Can "Fragile States" Decide to Reduce Their Deforestation? The Inappropriate Use of the Theory of Incentives with Respect to the REDD Mechanism. Forest Policy and Economics. 18, 38-45.

[26] Karsenty A., Vogel A. and Castell F., 2014. "Carbon Rights" REDD + and Payments for Environmental Services. Environmental Science \&3 Policy. 35, 20-29.

[27] Kerr S.C., 2013. The Economics of International Policy Agreements to Reduce Emissions from Deforestation and Degradation. Review of Environmental Economics and Policy. 7(1), 47-66.

[28] Kindermann G., Obersteiner M., Sohngen B., Sathaye J., Andrasko K., Rametsteiner E., Schlamadinger B., Wunder S. and Beach R., 2008. Global Cost Estimates of Reducing Carbon Emissions through Avoided Deforestation. Proceedings of the National Academy of Sciences (PNAS). 105, 10302-10307.

[29] Laffont J.-J. and Martimort D., 2002. The Theory of Incentives: the Principal-Agent Model. Princeton University Press.

[30] Laffont J.-J. and Tirole J., 1986. Using Cost Observation to Regulate Firms. Journal of Political Economy. 94(3), 614-641.

[31] Laing T. and Palmer C., 2015. Economy-Wide Impacts of REDD When There is Political Influence. Resource and Energy Economics. 40, 107-126.

[32] Lederer M., 2011. From CDM to REDD + -What Do We Know for Setting up Effective and Legitimate Carbon Governance? Ecological Economics. 70, 1900-1907. 
[33] MacKenzie I.A., Ohndorf M. and Palmer C., 2012. Enforcement-proof contracts with moral hazard in precaution: ensuring 'permanence' in carbon sequestration, Oxford Economic Papers, 64(2), 350-374, April.

[34] Martimort D. and Sand-Zantman W., 2016. A Mechanism Design Approach To ClimateChange Agreements. Journal of the European Economic Association. 14(3), 669-718.

[35] Maskin E. and Riley J., 1985. Input Versus Output Incentive Schemes. Journal of Public Economics. 28, 1-23.

[36] Mason C.F. and Plantinga A.J., 2013. The Additionality Problem with Offsets: Optimal Contracts for Carbon Sequestration in Forests. Journal of Environmental Economics and Management. 66(1), 1-14.

[37] Mather A., 1992, The Forest Transition. Area. 24, 367-379.

[38] Murray B.C., Lubowski R. and Sohngen B., 2009. Including International Forest Carbon Incentives in Climate Policy: Understanding the Economics. NI R 09-03 Nicholas Institute for Environmental Policy Solutions, Duke University, Durham, NC.

[39] Murray B. C., Busch J., Woodward R.T. and Jenkins A., 2013. Designing Cap and Trade to Correct for Non-Additional Offsets. Duke Environmental and Energy Economics Working Paper EE, 13-05.

[40] Myerson R.B., 1979. Incentive Compatibility and the Bargaining Problem. Econometrica. $47,61-74$.

[41] Obersteiner M., Huettner M., Kraxner F., McCallum I., Aoki K., Böttcher H., Fritz S., Gusti M., Havlik P., Kindermann G., Ramesteiner E. and Reyers B., 2009. On Fair, Effective and Efficient REDD Mechanism Design. Carbon Balance and Management. 4(11), 1-11.

[42] Ohler H., Nunnenkamp P. and Dreher A., 2012. Does Conditionality Work? A Test for an Innovative US Aid Scheme. European Economic Review. 56, 138-153.

[43] Ollivier H., 2012. Growth, Deforestation and the Efficiency of the REDD Mechanism. Journal of Environmental Economics and Management. 64, 312-327.

[44] Pfaff A., Amacher G. and Sills E.O., 2013. Realistic REDD: Improving the Forest Impacts of Domestic Policies in Different Settings. Review of Environmental Economics and Policy. $7(1), 114-135$. 
[45] Plantinga A.J. and Richards K.R., 2010. International Forest Carbon Sequestration in a Post-Kyoto Agreement. Discussion Paper 08-11. In: Aldy J.E. and Stavins R.N. (eds). PostKyoto International Climate Policy. New York, NY: Cambridge University Press.

[46] Salvini G., Herold M., De Sy V., Kissinger G., Brockhaus M. and Skutsch M., 2014. How Countries Link REDD + Interventions to Drivers in their Readiness Plans: Implications for Monitoring Systems. Environmental Research Letters. 9(7), 074004.

[47] Seyller C., Desbureaux S., Ongolo S., Karsenty A., Simonet G., Faure J. and Brimont L. 2016. The 'Virtual Economy' of REDD + Projects: Does Private Certification of REDD+ Projects Ensure Their Environmental Integrity?, International Forestry Review. 18(2), 231246.

[48] Sheriff G., 2009. Implementing Second-best Environmental Policy under Adverse Selection. Journal of Environmental Economics and Management, 57(3), 253-268.

[49] van Soest D. and Lensink R., 2000. Foreign Transfers and Tropical Deforestation: What Terms of Conditionality? American Journal of Agricultural Economics. 82, 389-399.

[50] Streck C., 2010. Reducing Emissions from Deforestation and Forest Degradation: National Implementation of REDD schemes (an Editorial Comment). Climatic Change. 100, 389-394.

[51] van der Werf G.R., Morton D.C., DeFries R., Olivier J.G.J., Kasibhatla P.S., Jackson R.B., Collatz G.J. and Randerson J.T., 2009. $\mathrm{CO}_{2}$ Emissions from Forest Loss. Nature Geoscience. 2, 737-738.

[52] Wirl F., Huber C. and Walker I.O., 1998. Joint Implementation: Strategic Reactions and Possible Remedies. Environmental \&3 Resource Economics. 12(2), 203-224.

[53] Wong G., Angelsen A., Brockhaus M., Carmenta R., Duchelle A., Leonard S., Luttrell C., Martius C. and Wunder S., 2016. Results-Based Payments for REDD+: Lessons on Finance, Performance, and Non-Carbon Benefits (Vol. 138). CIFOR. DOI 10.17528/cifor/006108.

[54] Wu J. and Babcock B.A., 1996. Contract Design for the Purchase of Environmental Goods from Agriculture. American Journal of Agricultural Economics, 78, 935-945.

[55] Zarin D., Angelsen A., Brown S., Loisel C., Peskett L. and Streck C., 2009. Reducing Emissions from Deforestation and Forest Degradation (REDD): An Options Assessment Report. Meridian Institute. 
Designing REDD + Contracts to Resolve Additionality Issues Figures

July 18, 2017 


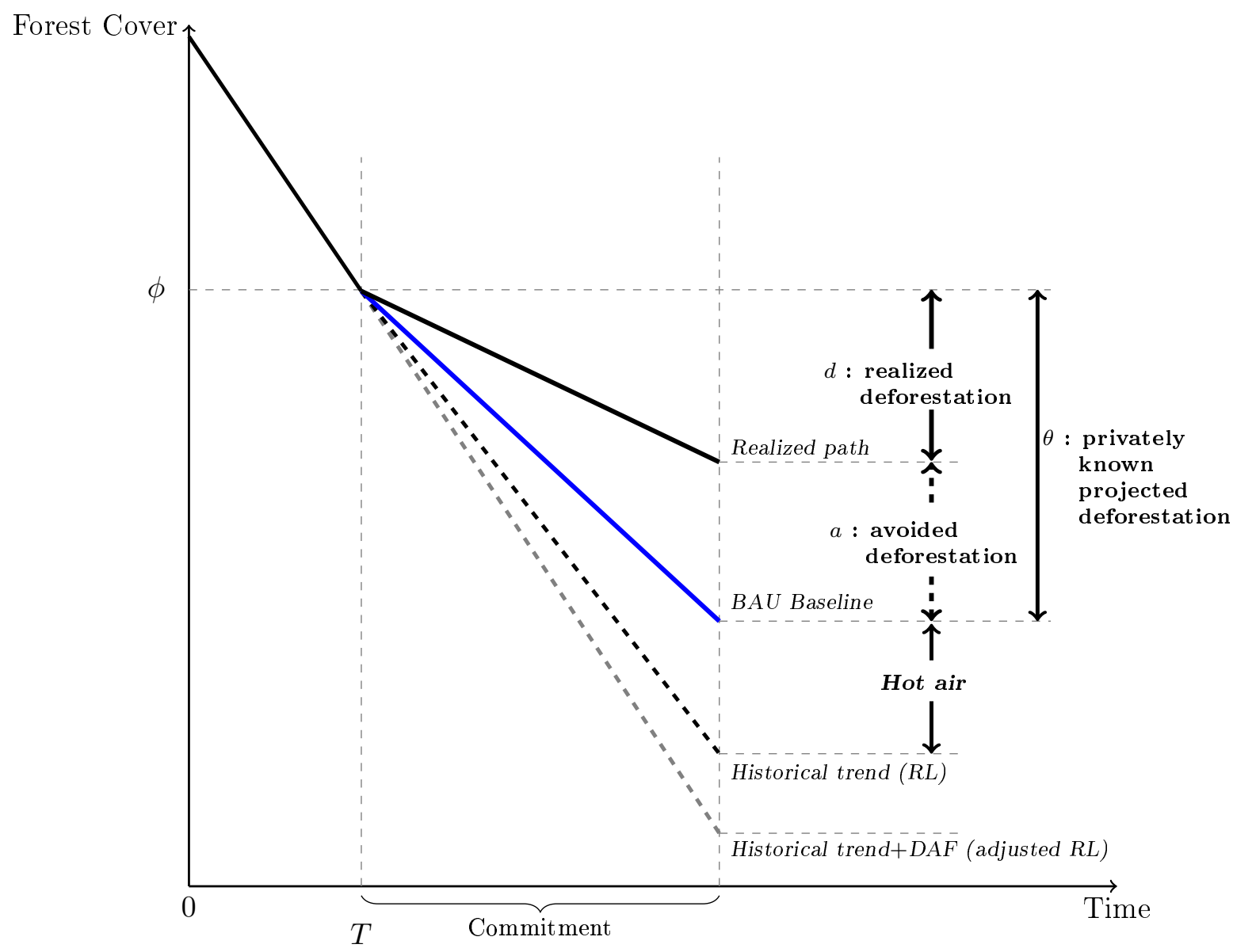

Figure 1: Business-as-usual deforestation baseline and reference levels 


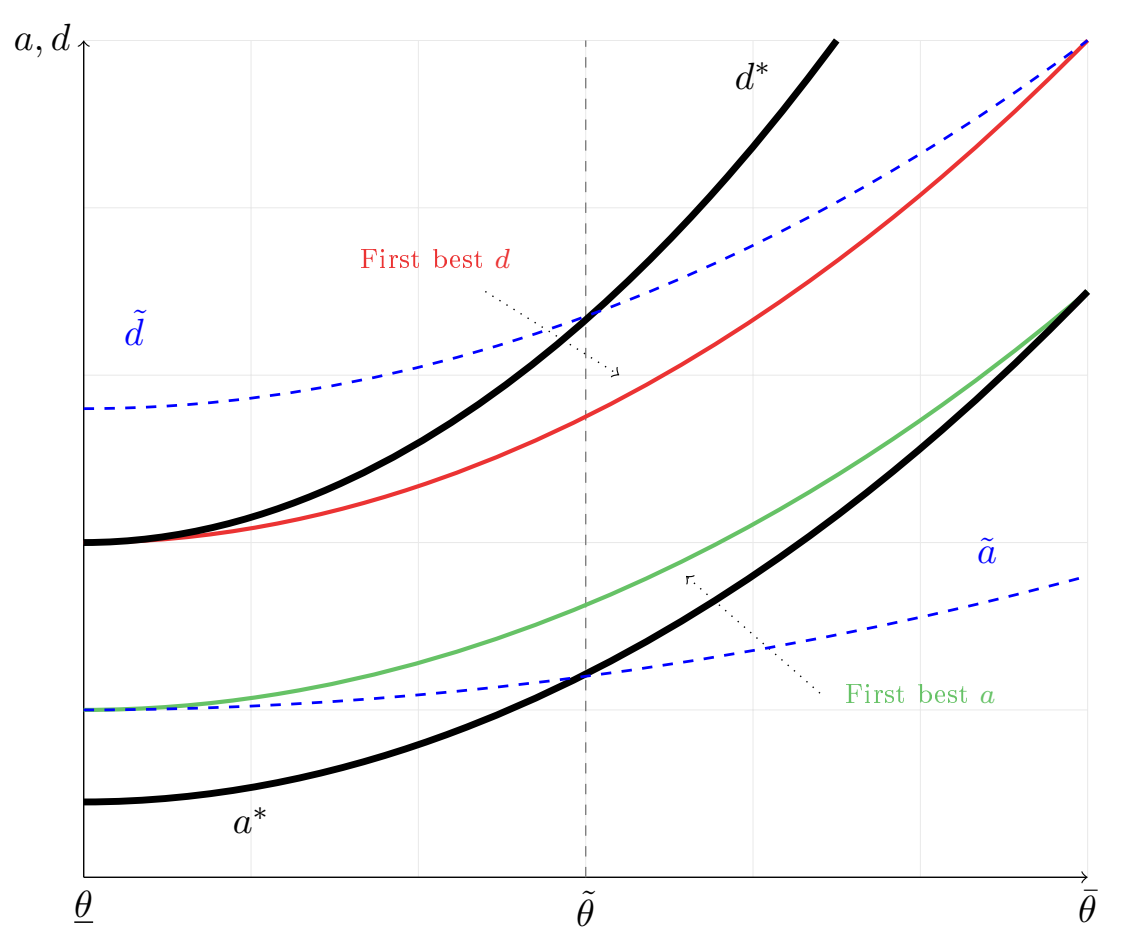

Figure 2: Comparison of REDD + schemes 